\title{
Imaging and treating tumor vasculature with targeted radiolabeled carbon nanotubes
}

This article was published in the following Dove Press journal:

International Journal of Nanomedicine

29 September 2010

Number of times this article has been viewed

\author{
Alessandro Ruggiero ${ }^{*}$ \\ Carlos H Villa ${ }^{* *}$ \\ Jason P Holland' \\ Shanna R Sprinkle' \\ Chad May ${ }^{2}$ \\ Jason S Lewis \\ David A Scheinberg' \\ Michael R McDevitt' \\ 'Departments of Medicine and \\ Radiology, Pharmacology and \\ Molecular Therapeutics, Memorial \\ Sloan-Kettering Cancer Center \\ New York, USA; ${ }^{2}$ ImClone Systems, \\ New York, USA; *Ruggiero and Villa \\ contributed equally to this work
}

\begin{abstract}
Single wall carbon nanotube (SWCNT) constructs were covalently appended with radiometal-ion chelates (1,4,7,10-tetraazacyclododecane-1,4,7,10-tetraacetic acid [DOTA] or desferrioxamine $\mathrm{B}[\mathrm{DFO}])$ and the tumor neovascular-targeting antibody E4G10. The E4G10 antibody specifically targeted the monomeric vascular endothelial-cadherin (VE-cad) epitope expressed in the tumor angiogenic vessels. The construct specific activity and blood compartment clearance kinetics were significantly improved relative to corresponding antibodyalone constructs. We performed targeted radioimmunotherapy with a SWCNT-([225 Ac]DOTA) (E4G10) construct directed at the tumor vasculature in a murine xenograft model of human colon adenocarcinoma (LS174T). The specific construct reduced tumor volume and improved median survival relative to controls. We also performed positron emission tomographic (PET) radioimmunoimaging of the tumor vessels with a SWCNT-([ $\left.\left.{ }^{89} \mathrm{Zr}\right] \mathrm{DFO}\right)(\mathrm{E} 4 \mathrm{G} 10)$ construct in the same murine LS174T xenograft model and compared the results to appropriate controls. Dynamic and longitudinal PET imaging of LS174T tumor-bearing mice demonstrated rapid blood clearance ( $<1$ hour) and specific tumor accumulation of the specific construct. Incorporation of the SWCNT scaffold into the construct design permitted us to amplify the specific activity to improve the signal-to-noise ratio without detrimentally impacting the immunoreactivity of the targeting antibody moiety. Furthermore, we were able to exploit the SWCNT pharmacokinetic (PK) profile to favorably alter the blood clearance and provide an advantage for rapid imaging. Near-infrared three-dimensional fluorescent-mediated tomography was used to image the LS174T tumor model, collect antibody-alone PK data, and calculate the number of copies of VE-cad epitope per cell. All of these studies were performed as a single administration of construct and were found to be safe and well tolerated by the murine model. These data have implications that support further imaging and radiotherapy studies using a SWCNT-based platform and focusing on the tumor vessels as the target.
\end{abstract}

Keywords: actinium-225 ( $\left.{ }^{225} \mathrm{Ac}\right)$, zirconium-89 $\left({ }^{89} \mathrm{Zr}\right)$, angiogenesis, vascular endothelialcadherin, radioimmunotherapy (RIT), radioimmunoPET

\section{Introduction}

Advances in cancer diagnosis and therapy require improvements in the agents used to image and treat disease. Valuable modifications include those that enable these agents to specifically target disease, increase signal-to-noise, rapidly clear from the blood, and incorporate multiple imaging and therapeutic modalities. Carbon nanomaterials are being investigated as delivery platforms for diagnostic and therapeutic cargoes to target disease. ${ }^{1,2}$ Pharmacokinetic (PK) studies of soluble, covalently-functionalized, radiolabeled carbon nanotubes (CNTs) have demonstrated rapid blood compartment
Correspondence: Michael R McDevitt Departments of Medicine and Radiology, Memorial Sloan-Kettering Cancer Center, 1275 York Ave, Box 23I,

New York, NY 10065, USA

Tel $+\mathrm{I}-646-888-2192$

$\mathrm{Fax}+\mathrm{I}-646-422-0640$

Email m-mcdevitt@ski.mskcc.org 
clearance, high specific activity (SA), multimodal imaging capability, renal elimination, and tumor-specific accumulation in vivo. ${ }^{3-6}$ Implementation of an imaging and therapeutic drug construct that is designed to target, report location, and irradiate the tumor vessels is a key strategic modification that will take advantage of the single wall CNT (SWCNT)-based construct's chemical, radiochemical, and PK properties.

Many cancers are characterized by an extensive angiogenic, aberrant vascular network that supports the tumor proliferation and survival. The endothelial vessels in tumors often do not exhibit the same organizational hierarchy of arterioles, capillaries, and venules present in normal tissue. Instead, tumor vessels are tortuous and have abnormal component and structural composition. Endothelial cells in these tumors are inefficiently and irregularly joined with holes, gaps, and defects; pericytes are absent or loosely associated with vessels; and basement membranes are inefficiently applied relative to typical normal tissues. The pore diameters of tumor typically range from 40 to $80 \mathrm{~nm}$. Large interendothelial junctions in cancerous tissue may be as large as $500 \mathrm{~nm}$, whereas in healthy tissue, these junctions are $\sim 8 \mathrm{~nm} .^{7}$ Angiogenic endothelial cells express the monomeric vascular endothelial-cadherin (VE-cad) epitope on the cell surface that upon dimerizing with another monomeric copy of VE-cad on an adjoining cell surface leads to the formation of tight adherens junctions between the cells. ${ }^{8-12}$ The antibody E4G10 binds only to the monomeric VE-cad and not to the homodimeric form (the binding region is masked in the homodimers that form the tight cell-cell contacts), thus conferring the specificity for targeting angiogenic and poorly joined endothelial cells in vivo while not binding to normal endothelium or the LS174T tumor.

The alpha particle-emitting radionuclide actinium-225 ( ${ }^{225} \mathrm{Ac} ; t_{1 / 2}=10$ days) attached to monoclonal antibodies (immunoglobulin [Ig]G) has been used as the therapeutic effector moiety in a number of preclinical studies ${ }^{13-18}$ and is currently in clinical use. ${ }^{19-21}$ Alpha particles are charged helium nuclei that travel $\sim 50-80 \mu \mathrm{m}$, which is similar to the dimensions of vessels within a tumor. The alpha particle track lengths appropriately match the vessel dimensions, and a single traversal through a cell of a high linear energy transfer (LET) alpha particle can be acutely cytotoxic. ${ }^{22,23}$ Typical tumor vasculature is $<100 \mu \mathrm{m}$ in diameter, and smaller vessels are $<10 \mu \mathrm{m}$ in diameter. In addition, individual alpha particles are able to kill a target cell due to their deposition of 5-8 MeV in a short ionizing track that is several cell diameters in length. ${ }^{23}$ This highly concentrated field of ionizing radiation may also irradiate the cancer stem cell population that can be found in the adjacent perivascular niche of some tumors. ${ }^{24-26}$ Alpha particles are very potent cytotoxic agents in proximity to the targeted tissue but will largely spare normal tissue; it is this characteristic that offers clear advantages to other known forms of radiation as a means of selective cell killing. We have previously demonstrated the utility of ${ }^{225}$ Ac-radiolabeled E4G10 constructs to target and irradiate tumor vascular endothelium in animal models, improve survival, control tumor growth, and normalize the vessels ${ }^{27}$ and also the ability of the construct to target and eradicate bone marrow-derived endothelial progenitors. ${ }^{28}$

Zirconium-89 ( ${ }^{89} \mathrm{Zr}$ ) is now being developed as one of the most promising new immuno-positron emission tomography (PET) agents for in vivo imaging of cancer. ${ }^{29-34} \mathrm{PET}$ is based on coincidence detection of a positron-emitting radionuclide from 2 coincident $511 \mathrm{keV}$ annihilation photons emitted simultaneously in opposite directions. ${ }^{35}$ The clinical use of PET has emerged as an important diagnostic imaging modality for humans because it provides extremely sensitive, quantitative, and functional information that is different from the information obtainable with other largely anatomical imaging modalities. ${ }^{35}$ The physical decay properties of ${ }^{89} \mathrm{Zr}$ $\left(t_{1 / 2}=78.41\right.$ hours; electron capture $\left.=76.6 \% ; \beta^{+}=22.3 \%\right)$ are well suited for use in the design of imaging agents with extended PK profiles. Recently, reported improvements in the separation chemistry of ${ }^{89} \mathrm{Zr}$ from the yttrium-89 $\left({ }^{89} \mathrm{Y}\right)$ target material have yielded a facile process for production of clinical-grade, high SA ${ }^{89} \mathrm{Zr}$ using a small cyclotron. ${ }^{30}$ This process should lead to more widespread use of this radionuclide.

The rationale for using SWCNTs as the scaffold in our construct design is the following: SWCNTs are made almost entirely of carbon, are nonimmunogenic, and can be chemically modified..$^{36-38}$ The commercially available SWCNTs have a diameter of 1-2 $\mathrm{nm}$ and lengths of $100-1,000 \mathrm{~nm}$. Thus, SWCNTs have extremely high aspect ratios with estimated surface areas of $1,600 \mathrm{~m}^{2} / \mathrm{g}$. On the atomic level, SWCNTs have highly regular structures with defined periodicity. For every $100 \mathrm{~nm}$ of length, a SWCNT can have up to 12,200 carbon atoms and weighs $150,000 \mathrm{Da}$, providing numerous sites (typically 1 in 95 carbons was modified) for chemical modifications and anchoring chemical, biological, and radionuclide moieties. ${ }^{3-6}$ SWCNTs that have been chemically functionalized with sidewall amino groups exhibit aqueous solubility and reactivity towards a variety of reagents under mild bioconjugation conditions..$^{3-6,36-39}$ The SWCNTs appended with amines and the metal-ion chelate 1,4,7,10-tetraazacyclododecane-1,4,7,10-tetraacetic acid 
(DOTA) were water soluble ( $20 \mathrm{~g} / \mathrm{L})$ and studied in vivo in animal models. ${ }^{3-6}$ Our data showed that these SWCNTs rapidly $\left(t_{1 / 2}<1\right.$ hour) cleared the blood and prototype SWCNT constructs $($ diameter $=\sim 1 \mathrm{~nm}$; length $=\sim 300 \mathrm{~nm}$; moleculer weight $=\sim 500 \mathrm{kD}$ ) were predominantly eliminated intact within minutes via glomerular filtration through the renal pathway. Renal excretion was found to be facilitated by the high aspect ratio of SWCNT, which confers lower rotational diffusivity; thus, the CNT tends to orient with the blood flow allowing easy access to the glomerular pores. ${ }^{6}$ Other recent work described the enzymatic degradation of functionalized SWCNT in vitro and in vivo, offering the potential for metabolic decomposition of CNT drug constructs. ${ }^{40-43}$ Further, toxicity studies have confirmed the safe in vivo use of functionalized SWCNT. ${ }^{44-47}$ Taken together, these data on renal elimination, enzymatic degradation, and lack of toxicity support continued investigation of SWCNT as a platform in drug development.

We hypothesize that CNT constructs can be covalently multifunctionalized with copies of targeting moieties and different reporting and therapeutic radionuclides and, thereby, increase signal-to-noise ratio and be used to image tumor vessels and improve the therapeutic index. The underlying rationale for this approach is that we are specifically targeting the aberrant and angiogenic tumor vessels and delivering a dose of short range ( $1-4$ cell diameters), high energy (several million electron volts) cytotoxic alpha particles to the targeted area. In addition, we will report the location of the drug construct. This approach is novel because it will examine the attributes of targeted radioimmunotherapy (RIT) with alpha particle generators, sensitive and quantitative PET imaging, and the specificity of the targeting E4G10 antibody in combination with the unique nanomaterial properties of SWCNT.

\section{Material and methods LSI74T xenograft model in nude mice}

Athymic nude mice (NCr nu/nu, male), 4-12 weeks of age, were obtained from Taconic, Germantown, NY, USA. For all in vivo experiments, housing and care were in accordance with the Animal Welfare Act and the Guide for the Care and Use of Laboratory Animals. The animal use protocols were approved by the Institutional Animal Care and Use Committee, Memorial Sloan-Kettering Cancer Center. Human LS174T cells (human colon adenocarcinoma) were expanded in Dulbecco-Vogt Modified Eagle's media supplemented with glucose, nonessential amino acids, L-glutamine, and $10 \%$ fetal bovine serum in an atmosphere of $5 \% \mathrm{CO}_{2}$ and air at $37^{\circ} \mathrm{C}$. Cells were harvested and mixed with Matrigel $^{\mathrm{TM}}$ (BD Biosciences, Palo Alto, CA, USA), and $0.1 \mathrm{~mL}$ of $\sim 2-3 \mathrm{E} 6$ cells were injected subcutaneously into the right hind flank of each animal.

\section{Construct design and syntheses}

SWCNTs (Nanolab, Newton, MA, USA) were covalently amine functionalized as described previously. ${ }^{3-6,36-39}$ The SWCNT-NH $\mathrm{N}_{2}$ product was purified from carbonaceous impurities using a C18 Sep-Pak ${ }^{\circledR}$ (Waters, Milford, MA, USA) and analyzed by high-performance liquid chromatography (HPLC), Raman spectroscopy, and transmission electron microscopy (TEM). ${ }^{3-6}$ Amine loading was determined using the Sarin assay, whereas TEM and Raman spectroscopy were performed as described previously. ${ }^{3-6}$ Table 1 provides a list of the key drug constructs, the corresponding nomenclature, studies performed, and the SA values for the therapeutic and imaging studies from this work.

The RIT drug Construct I (Figure 1A) was designed to specifically target the tumor vessels and deliver the potent alpha particle-emitting ${ }^{225} \mathrm{Ac}$ radionuclide generator. ${ }^{13}$ The key SWCNT precursor to Construct I was assembled by first converting a fraction of the primary amines on the SWCNT- $\mathrm{NH}_{2}$ construct to reactive hydrazinopyridine (HNH) moieties. Briefly, $0.5 \mathrm{~g}$ of SWCNT$\mathrm{NH}_{2}$ was dissolved in $1 \mathrm{~mL}$ of $100 \mathrm{mM}$ sodium phosphate $\left(\mathrm{NaH}_{2} \mathrm{PO}_{4}\right.$ and $\mathrm{Na}_{3} \mathrm{PO}_{4}$; Sigma-Aldrich, St Louis, $\mathrm{MO}$, USA)/150 mM sodium chloride ( $\mathrm{NaCl}$; Sigma-Aldrich), $\mathrm{pH}$ 7.8 buffer. Immediately before use, $5.5 \mathrm{mg}$ of succinimidyl 4-hydrazinonicotinate acetone hydrazone (SANH; Solulink Inc, San Diego, CA, USA) was dissolved in $0.2 \mathrm{~mL}$ of dry $N, N$-dimethylformamide (DMF; Sigma-Aldrich). An aliquot

Table I Construct nomenclature, designation, study use, and specific activity

\begin{tabular}{|c|c|c|c|c|}
\hline Construct nomenclature & Designation & Study & High SA (Ci/g) & Low SA (Ci/g) \\
\hline SWCNT-([225Ac]DOTA)(E4G I0) & Construct I & RIT & 23 & 0.05 \\
\hline SWCNT-([225Ac]DOTA)(anti-KLH) & Control Construct I & RIT & 23 & NA \\
\hline 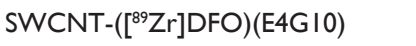 & Construct II & RII & 16 & NA \\
\hline SWCNT-([ $\left.\left.{ }^{89} \mathrm{Zr}\right] \mathrm{DFO}\right)($ anti-KLH) & Control Construct II & RII & 16 & NA \\
\hline
\end{tabular}

Abbreviations: SA, specific activity; SWCNT, single wall carbon nanotube; ${ }^{225}$ Ac, actinium-225; DOTA, I,4,7,10-tetraazacyclododecane-I,4,7,I0-tetraacetic acid; RIT, radioimmunotherapy; anti-KLH, anti-keyhole limpet hemocyanin; ${ }^{89} \mathrm{Zr}$, zirconium-89 DFO, desferrioxamine B; RII, radioimmunoimaging. 


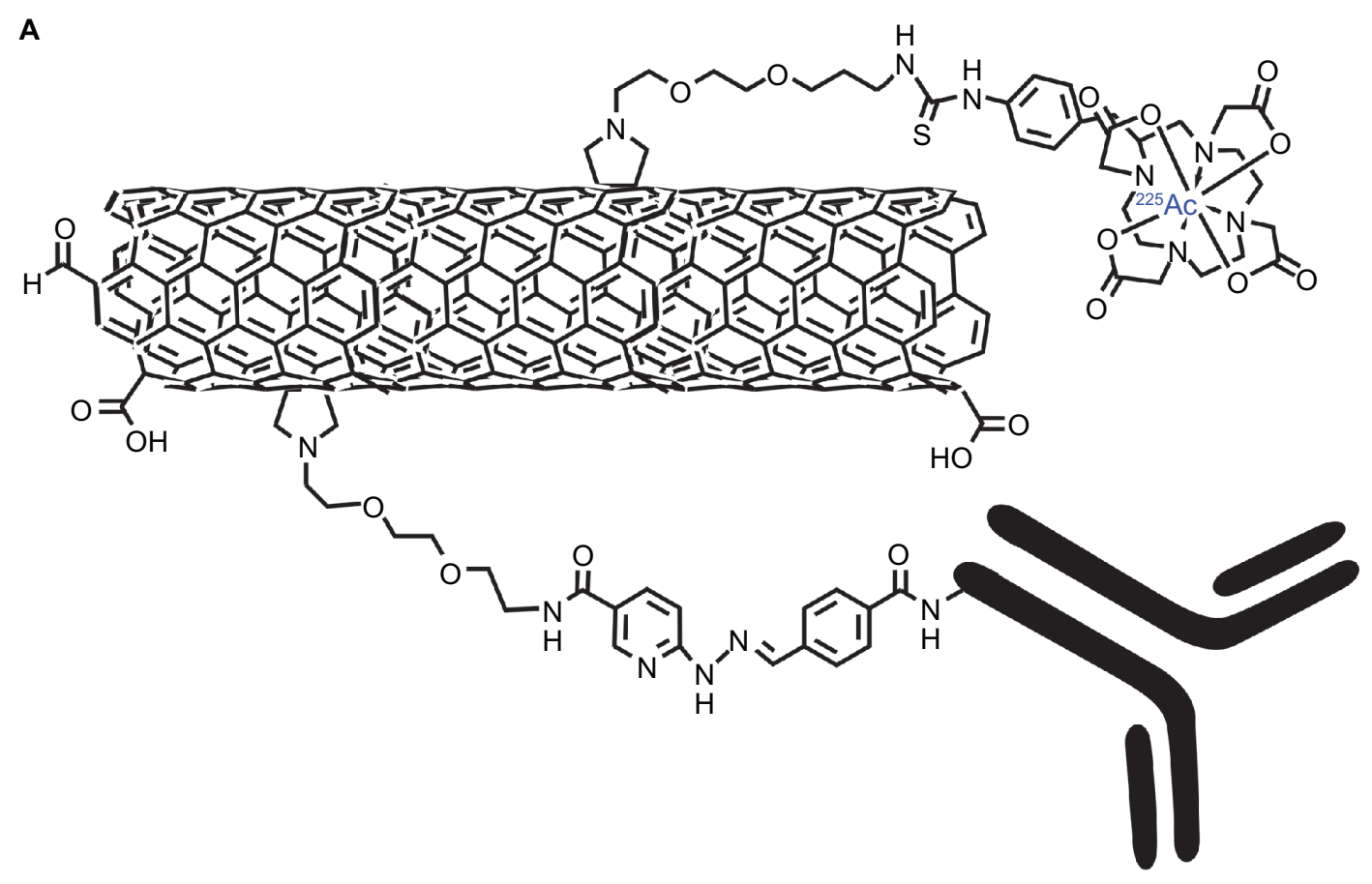

B
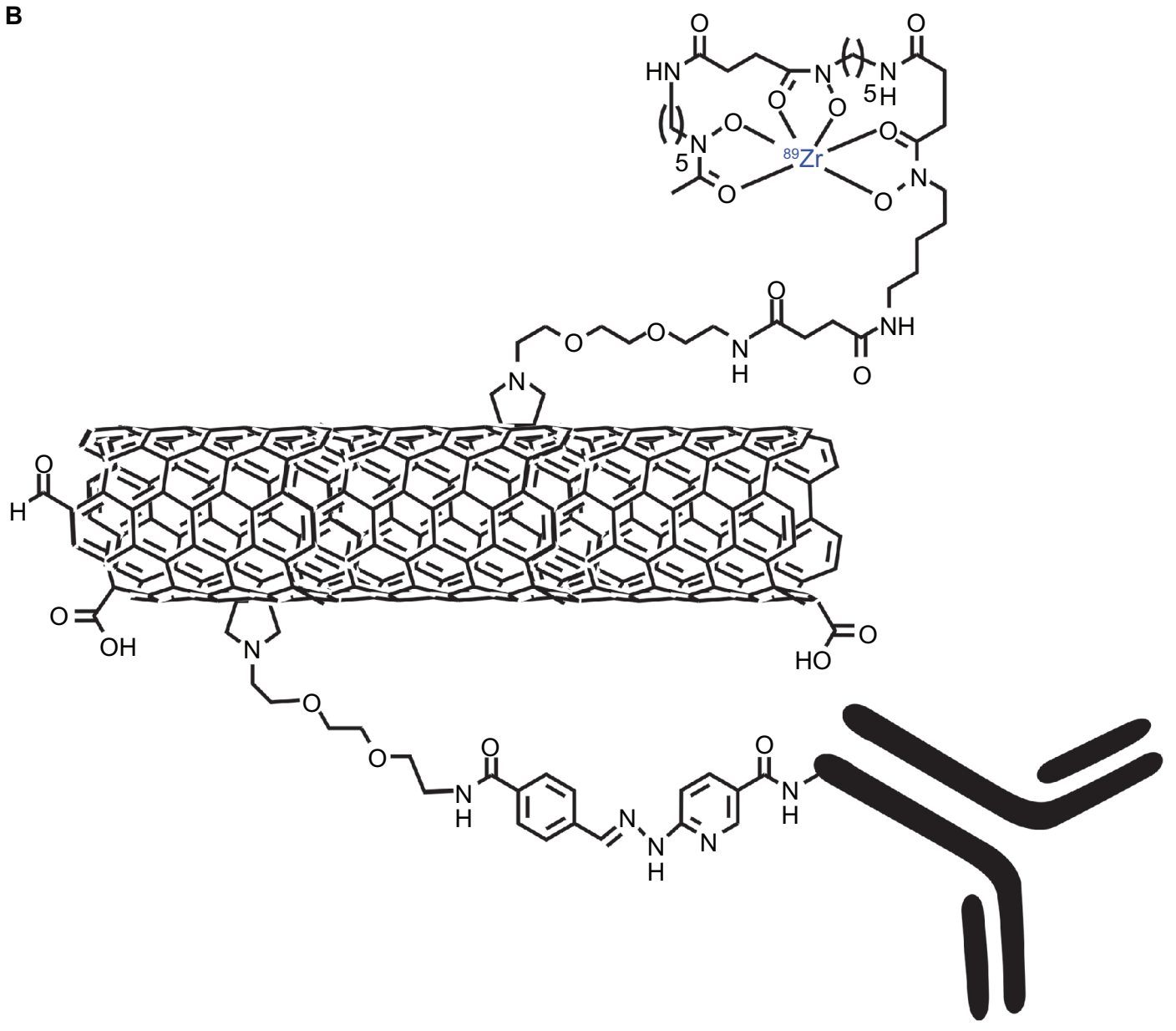

Figure I Graphical representations of the key moieties that were appended to the water-soluble SWCNT-NH by covalent-functionalization with radionuclides, DOTA, DFO, and antibodies (Note, not drawn to scale). A) Radioimmunotherapeutic drug Construct I (SWCNT-([225 Ac]DOTA)(E4G I0)). B) Radioimmunoimaging drug Construct II SWCNT-([98r]DFO)(E4G I0).

Abbreviations: SWCNT, single wall carbon nanotube; DOTA, I,4,7, I0-tetraazacyclododecane-I,4,7,I0-tetraacetic acid; DFO, desferrioxamine B; ${ }^{225} \mathrm{Ac}$, actinium-225; ${ }^{89} \mathrm{Zr}$, zirconium-89. 
of SANH/DMF solution was added to the SWCNT-NH $\mathrm{SH}_{2}$ to achieve a 0.25 -fold mole ratio of SANH to primary amine. The reaction proceeded at ambient temperature for 2-3 hours at $\mathrm{pH}$ 7.6. The product, SWCNT-(HNH)( $\left.\mathrm{NH}_{2}\right)$, was purified using size exclusion chromatography (SEC) with a $10 \mathrm{DG}$ gel permeation column (Bio-Rad Laboratories, Hercules, CA, USA) as the stationary phase and metal-free water (MFW; Purelab Plus System, US Filter Corp, Lowell, MA, USA) as the mobile phase. The product was lyophilized to yield a solid that was found to be the desired SWCNT- $(\mathrm{HNH})\left(\mathrm{NH}_{2}\right)$ construct.

The second step entailed covalently appending multiple copies of 2-( $p$-isothiocyanatobenzyl)-DOTA (DOTA-NCS; Macrocyclics, Inc, Dallas, TX, USA) to the remaining amines on the water-soluble SWCNT- $(\mathrm{HNH})\left(\mathrm{NH}_{2}\right)$ construct to yield a SWCNT-(DOTA)(HNH) construct in metal-free conditions at $\mathrm{pH} 9.5$ (adjusted with $1 \mathrm{M}$ metal-free carbonate solution) for 40 minutes at room temperature at a stoichiometry of 10:1 (DOTA-NCS to amine)..$^{3-6}$ The product was purified using a 10 DG gel permeation column with MFW as the mobile phase. The 10 DG column was rendered metal free by washing with $50 \mathrm{~mL}$ of $25 \mathrm{mM}$ EDTA (Sigma-Aldrich) followed by rinsing with $250 \mathrm{~mL}$ of MFW. The product was lyophilized to yield a solid that was found to be the desired SWCNT-(DOTA)(HNH) construct.

\section{SWCNT-(DOTA) $(\mathrm{HNH})+{ }^{225} \mathrm{Ac} \rightarrow$ SWCNT-([225Ac]DOTA $)(\mathrm{HNH})$}

${ }^{225} \mathrm{Ac}$ radionuclide was obtained from the US Department of Energy's Oak Ridge National Laboratory (Oak Ridge, TN, USA). Methods for radiolabeling and purification of a MFW solution of SWCNT-(DOTA)(HNH) with ${ }^{225} \mathrm{Ac}$ at $\mathrm{pH} 5$ are similar to those described previously. ${ }^{48}$ Briefly, $0.18 \mathrm{mg}$ of SWCNT-(DOTA)(HNH) in $0.02 \mathrm{~mL}$ of MFW was reacted with $0.005 \mathrm{~mL}$ of ${ }^{225} \mathrm{Ac}$ in $50 \mathrm{mM}$ optima grade hydrochloric acid ( $\mathrm{HCl}$; Fisher Scientific, Pittsburgh, PA, USA) along with $0.02 \mathrm{~mL}$ of $150 \mathrm{~g} / \mathrm{L}$ L-ascorbic acid (Sigma-Aldrich) and $0.2 \mathrm{~mL}$ of $3 \mathrm{M}$ tetramethylammonium acetate (Fisher Scientific) buffer, $\mathrm{pH} 5.5$, at $60^{\circ} \mathrm{C}$ for 60 minutes (reaction 1). Purification was accomplished using SEC with a P6 gel stationary phase and a phosphate buffer saline (PBS) mobile phase. Chemicals used in the radiolabeling and purification steps were of American Chemical Society reagent-grade or higher purity. The labeling solutions were prepared and subsequently rendered metal free with Chelex ${ }^{\circledR} 100$ resin, 200-400 mesh, sodium form (Bio-Rad Laboratories), and sterile filtered through a 0.22 or $0.45 \mu \mathrm{m}$ filter device. Solutions of $50 \mathrm{mM}$ diethylenetriaminepentaacetic acid (DTPA; Sigma-Aldrich) were sterile filtered and used to quench the labeling reaction prior to SEC. Human serum albumin (HSA; Swiss Red Cross, Bern, Switzerland) and $0.9 \% \mathrm{NaCl}$ (Abbott Laboratories, North Chicago, IL, USA) were used as received. ${ }^{225} \mathrm{Ac}$ activity was measured with a Squibb CRC-17 Radioisotope Calibrator (or equivalent model; E.R. Squibb and Sons, Inc, Princeton, NJ, USA) set at 775 and multiplying the displayed activity value by 5 to report the activity.

Instant thin layer chromatography using silica gel impregnated paper (ITLC-SG; Gelman Science Inc, Ann Arbor, MI, USA) was used to determine the labeling efficiency of the reaction mixture and the purity of the product. Briefly, a $0.001 \mathrm{~mL}$ aliquot was spotted onto the paper strips and developed using 2 different mobile phases. ${ }^{13,23,48}$ Mobile phase 1 was $10 \mathrm{mM}$ EDTA and 2 was $9 \% \mathrm{NaCl} / 10 \mathrm{mM}$ sodium hydroxide $(\mathrm{NaOH}$; SigmaAldrich). The $\mathrm{R}_{\mathrm{f}}$ of the radiolabeled construct was 0 and any free metal species and metal chelates were characterized by $\mathrm{R}_{\mathrm{f}}$ of 1.0 in mobile phase 1 . In mobile phase 2 , the radiolabeled construct and free metal species were characterized by $R_{f}$ of 0 and the metal chelates by $R_{f}$ of 1.0 . The strips were counted intact using a System 400 Imaging Scanner (Bioscan Inc, Washington, USA).

$$
\mathrm{E} 4 \mathrm{G} 10+\mathrm{SFB} \rightarrow \mathrm{E} 4 \mathrm{G} 10-\mathrm{FB}
$$

The next key step (reaction 2) was the conversion of the VE-cad-specific IgG (E4G10; Imclone Systems, New York, NY, USA) or the isotype control anti-keyhole limpet hemocyanin (anti-KLH) IgG (R\&D Systems, Minneapolis, MN, USA) to the reactive arylaldehyde modified-IgG precursors. Briefly, immediately before use, $15 \mathrm{mg}$ of succinimidyl 4-formylbenzoate (SFB; Solulink Inc) was dissolved in $0.5 \mathrm{~mL}$ DMF. An aliquot of this modification solution was added to $2.5 \mathrm{mg}$ of $\mathrm{E} 4 \mathrm{G} 10$ protein $(5 \mathrm{~g} / \mathrm{L}$; or the isotype control $\mathrm{IgG}$ ) to achieve a 10-20 fold molar excess of the reagent. The reaction mixture was incubated at $37^{\circ} \mathrm{C}$ for 2-3 hours. Purification of the arylaldehyde modified-IgG was performed by SEC as described above. The modified proteins were stored at $4^{\circ} \mathrm{C}$. The stoichiometry of substitution (moles of formylbenzoate [FB] per mole IgG) was determined first by assaying the protein concentration using the bicinchoninic acid (BCA) protein assay (Pierce, Rockford, IL, USA) and the moles of FB per mole IgG using the 2-HNH-dihydrochloride (2-HP; Solulink) quantification assay. Briefly, the addition of a molar excess 2-HP to the FB moiety on E4G10 at pH 4.7 permitted the measurement of the molar substitution ratio by 
electronic absorption spectroscopy using the arylhydrazone chromophore (maximum absorption $\left[\mathrm{Abs}_{\max }\right]=350 \mathrm{~nm}$, $\left.\varepsilon=18,000 \mathrm{M}^{-1} \mathrm{~cm}^{-1}\right)$.

$$
\begin{aligned}
& \text { SWCNT- }\left(\left[{ }^{225} \text { Ac }\right] \text { DOTA }\right)(\mathrm{HNH})+\mathrm{E} 4 \mathrm{G} 10-\mathrm{FB} \rightarrow \\
& \quad \text { SWCNT- }\left(\left[{ }^{225} \text { Ac }\right] \text { DOTA }\right)(\mathrm{E} 4 \mathrm{G} 10)
\end{aligned}
$$

The E4G10-FB antibodies were covalently attached to the SWCNT-([225 Ac]DOTA)(HNH) by the reaction of $0.05 \mathrm{mg}$ of SWCNT-([225Ac]DOTA)(HNH) with $0.17 \mathrm{mg}$ of E4G10-FB in $1.2 \mathrm{~mL}$ of $100 \mathrm{mM}$ sodium phosphate/150 $\mathrm{mM} \mathrm{NaCl}$, pH 5.2 buffer (reaction 3). A similar chemical scheme was used to append several of the anti-KLH-FB moieties to the SWCNT-([225Ac]DOTA)(HNH) precursor to yield the control Construct I. The reaction mixture was incubated at $37^{\circ} \mathrm{C}$ for several hours, and the high and low SA SWCNT- $\left(\left[{ }^{225} \mathrm{Ac}\right]\right.$ DOTA)(E4G10) (Construct I) and isotype control Construct I products were stored at $4^{\circ} \mathrm{C}$. The products were formulated into $1 \% \mathrm{HSA}$ for injection.

The radioimmunoimaging (RII) drug Construct II (Figure 1B) was designed to specifically target the tumor vessels and deliver the positron-emitting ${ }^{89} \mathrm{Zr}$ radionuclide for PET imaging. The key precursor to Construct II was assembled first by appending multiple copies of the reactive arylaldehyde, SFB. Briefly, the SFB was dissolved in $0.1 \mathrm{~mL}$ $\mathrm{DMF}$ and a volume of this modification solution was added to $0.5 \mathrm{mg}$ of SWCNT-NH $\mathrm{SH}_{2}(3 \mathrm{~g} / \mathrm{L})$ to achieve a ratio of $5 \mathrm{SFB}$ per 100 amines. The reaction mixture was incubated at $37^{\circ} \mathrm{C}$ for 2-3 hours. Purification of the arylaldehyde modifiedSWCNT was performed by SEC as described above. The stoichiometry of substitution was determined (moles of FB per gram SWCNT) using the 2-HP quantification assay as described previously. Then, the remaining amines on the SWCNT-(FB) $\left(\mathrm{NH}_{2}\right)$ construct were covalently modified by appending the desferrioxamine B (DFO) chelate. The details of preparation of the reactive DFO intermediate reagent are described below.

The synthesis of $N$-succinylDFO ( $N$-succDFO) was performed by the reaction of DFO mesylate $(0.508 \mathrm{~g}$, 0.77 mmol; Calbiochem, Spring Valley, CA, USA) dissolved in $7.5 \mathrm{~mL}$ of pyridine (Sigma-Aldrich) with excess (1.704 g, $0.017 \mathrm{~mol}$ ) succinic anhydride (Sigma-Aldrich) at room temperature for 24 hours. The resulting white suspension was then poured into an aqueous $\mathrm{NaOH}$ solution $(120 \mathrm{~mL}$, $0.015 \mathrm{M}$ ) and stirred at room temperature for 16 hours. The colorless solution was adjusted to $\mathrm{pH} 2$ by the addition of 12 $\mathrm{M} \mathrm{HCl}$ and cooled with stirring at $4^{\circ} \mathrm{C}$ for 2 hours. The white precipitate was collected by filtration, washed with copious amounts of $0.01 \mathrm{M} \mathrm{HCl}$ and then water, and dried in a vacuum to give the $N$-succDFO as a white microcrystalline solid (0.306 g, $\left.4.75 \times 10^{-4} \mathrm{~mol}\right)$.

The preparation of ferric DFO-2,3,5,6-tetrafluorophenol (Fe[DFO-TFP]) was performed by reacting the activated ester $N$-succDFO (9.0 mg, $0.014 \mathrm{mmol})$, suspended in $3 \mathrm{~mL}$ of $0.9 \%$ sterile saline and the $\mathrm{pH}$ adjusted to 6.5 , with $0.05-0.075 \mathrm{~mL}$ of $0.1 \mathrm{M}$ sodium carbonate ( $\mathrm{Na}_{2} \mathrm{CO}_{3}$; Sigma-Aldrich). A solution of ferric trichloride hexahydrate $\left(\mathrm{FeCl}_{3} 6 \mathrm{H}_{2} \mathrm{O}[4 \mathrm{mg}, 0.015 \mathrm{mmol}, 0.3 \mathrm{~mL}\right.$ of 0.1 $\mathrm{M} \mathrm{HCl}$; Sigma-Aldrich) - was added to this $N$-succDFO solution. Upon addition of the $\mathrm{FeCl}_{3}$, the reaction mixture changed from colorless to deep orange due to the intense electronic absorption band of $\mathrm{Fe}(\mathrm{DFO})$ with a peak at $430 \mathrm{~nm}\left(\varepsilon_{430}=2,216 \pm 49 \mathrm{M}^{-1} \mathrm{~cm}^{-1}\right)$. After stirring the reaction mixture at room temperature for 1 hour, a $1.2 \mathrm{M}$ solution of TFP (0.3 mL, $0.036 \mathrm{mmol}$; Sigma-Aldrich) in Chelex-purified acetonitrile (MeCN; Sigma-Aldrich) was added to the reaction followed by the addition of solid $N$-(3-dimethylaminopropyl)- $N$ '-ethylcarbodiimide hydrochloride (0120 mg, $0.63 \mathrm{mmol}$; Sigma Aldrich). The reaction mixture ( $\mathrm{pH}$ 6.5) was then stirred at room temperature for 1 hour before purifying the Fe(DFO-TFP) product using a C18 Light Sep-Pak cartridge (Waters). The reaction mixture was loaded onto a preactivated $(6 \mathrm{~mL}$ $\mathrm{MeCN}$ and $\left.10 \mathrm{~mL} \mathrm{H}_{2} \mathrm{O}\right) \mathrm{C} 18$ cartridge, washed with copious amounts of water $(>40 \mathrm{~mL})$, and eluted with $1.5 \mathrm{~mL}$ $\mathrm{MeCN}$. The final Fe(DFO-TFP) solution had a concentration of $\sim 9.8 \mathrm{mM}$. The Fe(DFO-TFP) solution was stored at $4^{\circ} \mathrm{C}$.

The Fe(DFO-TFP) reagent was then reacted with the remaining amines on the SWCNT-(FB) $\left(\mathrm{NH}_{2}\right)$ construct to introduce the DFO chelate onto the SWCNT precursor. The Fe was removed by exposing the metallated precursor to a 10-fold excess of EDTA $(0.0674 \mathrm{M}, 0.0137 \mathrm{mmol}$, $0.03 \mathrm{~mL})$ with respect to $\mathrm{Fe}(N$-succDFO-TFP). The reaction was incubated in a water bath at $38^{\circ} \mathrm{C}$ for 1 hour. The SWCNT-(DFO)(FB) was purified by SEC chromatography to render it $\mathrm{Fe}$ free and was ready to be radiolabeled (reaction 4).

$$
\begin{gathered}
\text { SWCNT-(DFO)(FB) }+{ }^{89} \mathrm{Zr} \rightarrow \\
\text { SWCNT-([89 } \rightarrow \text { r }] \text { DFO)(FB) }
\end{gathered}
$$

${ }^{89} \mathrm{Zr}$ was produced via the ${ }^{89} \mathrm{Y}(\mathrm{p}, \mathrm{n}){ }^{89} \mathrm{Zr}$ transmutation reaction on an EBCO TR19/9 variable-beam-energy cyclotron (Ebco Industries Inc, Richmond, BC, Canada) in accordance with previously reported methods. ${ }^{30}$ The 
${ }^{89} \mathrm{Zr}$-oxalate was isolated in high radionuclidic and radiochemical purity $(\mathrm{RCP})>99.9 \%$, with an effective SA of $195-497 \mathrm{TBq} / \mathrm{g},(5,280-13,430 \mathrm{Ci} / \mathrm{g}) .{ }^{30}$ Methods for radiolabeling and purification of a $10 \mathrm{~g} / \mathrm{L}$ solution of SWCNT-(DFO)(FB) in MFW with ${ }^{89} \mathrm{Zr}$ at $\mathrm{pH} 5$ are similar to those described previously. ${ }^{30}$ Briefly, $0.1 \mathrm{mg}$ of SWCNT-(DFO)(FB) in $0.02 \mathrm{~mL}$ of MFW was reacted with $122.5 \mathrm{MBq}(3.31 \mathrm{mCi})$ of ${ }^{89} \mathrm{Zr}$ in $0.005 \mathrm{~mL}$ of $1 \mathrm{M}$ oxalic acid (Sigma-Aldrich), $\mathrm{pH}$ 6.5. The $\mathrm{pH}$ was adjusted to 8.1 with the addition of $0.17 \mathrm{~mL}$ of $1.0 \mathrm{M} \mathrm{Na}_{2} \mathrm{CO}_{3}$. The reaction was heated to $60^{\circ} \mathrm{C}$ for 60 minutes. Purification was accomplished using SEC with a P6 gel stationary phase and a PBS mobile phase. ${ }^{89} \mathrm{Zr}$ activity was measured with a Squibb CRC-17 Radioisotope Calibrator (or equivalent model) set at 465. ITLC-SG was used to determine the labeling efficiency of the reaction mixture and the purity of the product. The strips were counted intact using a System 400 Imaging Scanner (or equivalent).

$$
\mathrm{E} 4 \mathrm{G} 10+\mathrm{SANH} \rightarrow \mathrm{E} 4 \mathrm{G} 10-\mathrm{HNH}
$$

The next key step was the conversion of the E4G10 or the isotype control anti-KLH IgGs to the reactive arylhydrazine modified-IgG precursors (reaction 5). Briefly, $1 \mathrm{mg}$ of IgG was dissolved in $0.2 \mathrm{~mL}$ of $100 \mathrm{mM}$ sodium phosphate/150 mM NaCl, pH 7.6 buffer. Immediately before use, 2-4 mg of SANH was dissolve in $0.1 \mathrm{~mL}$ of dry DMF. A volume of SANH/DMF solution was added to the IgG to achieve a 10-20 fold molar excess of the $\mathrm{SANH}$ to antibody. The reaction proceeded at ambient temperature for 2-3 hours at $\mathrm{pH}$ 7.6. The product, IgG$\mathrm{HNH}$, was purified using SEC with a $10 \mathrm{DG}$ gel column as the stationary phase and $100 \mathrm{mM} 2-(N$-morpholino $)$ ethanesulfonic acid (MES; Sigma-Aldrich)/150 mM $\mathrm{NaCl}$ conjugation buffer at $\mathrm{pH} 5.4$ as the mobile phase. The amount of HNH substituent per IgG was determined first by assaying the protein concentration using the BCA protein assay and the moles of arylhydrazine (HNH) per mole IgG using the 4-nitrobenzaldehyde (4-NBA; Solulink) quantification assay. Addition of a molar excess 4-NBA to the $\mathrm{HNH}$ moiety on IgG at $\mathrm{pH} 4.7$ permitted the measurement of the molar substitution ratio of the chromophore $\left(\mathrm{Abs}_{\max }=390 \mathrm{~nm}, \varepsilon=24,000 \mathrm{M}^{-1} \mathrm{~cm}^{-1}\right)$.

$$
\begin{aligned}
& \text { SWCNT- }\left(\left[{ }^{89} \mathrm{Zr}\right] \mathrm{DFO}\right)(\mathrm{FB})+\mathrm{E} 4 \mathrm{G} 10-\mathrm{HNH} \rightarrow \\
& \left.\left.\quad \text { SWCNT-([}{ }^{89} \mathrm{Zr}\right] \mathrm{DFO}\right)(\mathrm{E} 4 \mathrm{G} 10)
\end{aligned}
$$

The E4G10-HNH antibodies (or anti-KLH-HNH) were covalently attached to the SWCNT-([ $\left.\left.{ }^{89} \mathrm{Zr}\right] \mathrm{DFO}\right)(\mathrm{FB})$ by the reaction of $0.1 \mathrm{mg}$ of SWCNT-([ $\left.\left.{ }^{89} \mathrm{Zr}\right] \mathrm{DFO}\right)(\mathrm{FB})$ with $0.3 \mathrm{mg}$ of E4G10-HNH in $0.25 \mathrm{~mL}$ of $100 \mathrm{mM} \mathrm{MES} / 150 \mathrm{mM} \mathrm{NaCl}$ conjugation buffer at $\mathrm{pH} 4.7$ (reaction 6). The reaction mixture was incubated at $37^{\circ} \mathrm{C}$ for several hours. The SWCNT- $\left(\left[{ }^{89} \mathrm{Zr}\right]\right.$ DFO)(E4G10) (Construct II) and isotype control Construct II products were stored at $4^{\circ} \mathrm{C}$ and were formulated into $1 \%$ HSA for injection.

\section{Amplification of construct specific activity}

A fixed mass of SWCNT-(DOTA)(HNH) precursor was radiolabeled with varying amounts of ${ }^{225} \mathrm{Ac}$ activity to determine the reaction yields and specific activities. In each of 5 radiolabeling reactions, the volume, $\mathrm{pH}$, time, temperature, and reagent concentrations were held constant (see specific conditions described above), while only the amount of radionuclide was varied. Briefly, $0.18 \mathrm{mg}$ of SWCNT-(DOTA)(HNH) was ${ }^{225} \mathrm{Ac}$-radiolabeled in $0.4 \mathrm{~mL}$, at $\mathrm{pH} 5.5$, at $60^{\circ} \mathrm{C}$ for 60 minutes in 5 different reactions. In amplification reaction 1 , the SWCNT-(DOTA) (HNH) was labeled with $0.444 \mathrm{MBq}(0.012 \mathrm{mCi}) ; 2,1.48$ $\mathrm{MBq}(0.04 \mathrm{mCi})$ was used; $3,2.26 \mathrm{MBq}(0.061 \mathrm{mCi})$ was used; 4, 21.1 MBq (0.57 mCi) was used; and 5, $193 \mathrm{MBq}$ $(5.21 \mathrm{mCi})$ was used. An aliquot of each reaction was assayed using ITLC-SG (see above), and then, the reaction was quenched with the addition of DTPA. The reaction mixture was then purified by SEC (see above) and the purified product assayed by ITLC-SG and the recovered activity measured.

Data for numerous preclinical radiolabeling preparations of ${ }^{225} \mathrm{Ac}-\mathrm{E} 4 \mathrm{G} 10$ were also compiled for comparison. The radiolabeling data using our published methods ${ }^{48}$ from 11-dose preparations that used $0.75 \pm 0.13 \mathrm{mg}$ (mean \pm standard deviation) of E4G10 and 93.6 \pm 51.1 $\mathrm{MBq}(2.53 \pm 1.38 \mathrm{mCi})$ of ${ }^{225} \mathrm{Ac}$ per dose were used as comparison to the results from the SWCNT-(DOTA) $(\mathrm{HNH})$ labeling study.

As a further demonstration of the consistency of our published 2-step IgG radiolabeling methodology, lintuzumab (Protein Design Labs, Inc, Mountain View, CA, USA), a monoclonal IgG that targets CD33 on leukemia cells, was routinely radiolabeled with ${ }^{225} \mathrm{Ac}$ for a Phase I clinical trial to produce ${ }^{225} \mathrm{Ac}$-lintuzumab. The radiolabeling data from 17 clinical dose preparations that used $1.4 \pm 0.5 \mathrm{mg}$ (mean \pm standard deviation) of lintuzumab and $91 \pm 55.1$ $\mathrm{MBq}(2.46 \pm 1.49 \mathrm{mCi})$ of ${ }^{225} \mathrm{Ac}$ were also included as comparison to the results from the SWCNT-(DOTA)(HNH) labeling study. 


\section{Three-dimensional fluorescent- mediated tomography imaging study to assess the PK of E4GIO and determine the number of VE-cad monomer epitopes per cell in vivo}

Three-dimensional fluorescent-mediated tomography (FMT) experiments were performed by using the FMT-2500 (VisEn Medical, Boston, MA, USA) to determine the PK profile of the of E4G10 (and anti-KLH isotype control) IgGs and the number of binding sites per newly formed vascular endothelial cell in the LS174T xenograft model.

The E4G10 and anti-KLH antibodies were reacted with the succinimidyl ester of Alexa Fluor ${ }^{\circledR} 680$ carboxylic acid (AF680; Invitrogen, Carlsbad, CA, USA) per the manufacturer's instructions to prepare 2 antibody constructs for an in vivo near-infrared (NIR) FMT imaging study. Briefly, the constructs were prepared by the reaction of a 10-20 fold mole excess of the succinimidyl ester of the AF680 dye per milligram of IgG at $\mathrm{pH} 8$ for 2 hours at ambient temperature. The dye-labeled constructs were purified by SEC chromatography as described above and characterized by UV-visible spectroscopy (measured the absorbance at 280 and $679 \mathrm{~nm}$ per the manufacturer's instructions) and SEC HPLC. The HPLC system used a Beckman Coulter System Gold Bioessential 125/168 diode array detection system (Beckman Coulter, Fullerton, CA, USA) equipped with an in-line Jasco FP-2020 fluorescence detector (Tokyo, Japan). The stationary phase was a Tosoh Science G3000SWXL column (300 mm $\times 7.8 \mathrm{~mm}, 5 \mu \mathrm{m}$; Fisher Scientific) and a $20 \mathrm{mM}$ sodium acetate (Sigma-Aldrich), $150 \mathrm{mM} \mathrm{NaCl}, \mathrm{pH}$ 6.4 , mobile phase at $1 \mathrm{~mL} / \mathrm{min}$ at ambient temperature.

Two groups of 5 nude mice with the LS174T tumor were randomly assembled, and each mouse received $0.03 \mathrm{mg}$ of the construct in $0.1 \mathrm{~mL}$ in $1 \% \mathrm{HSA}$ via intravenous (IV) retro-orbital sinus injection. NIR FMT imaging was performed every $24-48$ hours over a 7 -day time period by using the specific 680 channel (excitation/emission [Ex/Em]: $680 \mathrm{~nm} / 700 \mathrm{~nm}$ ). The volume of interest (VOI) was drawn over the whole tumor (as visualized by the 3-dimensional photographic image acquisition), and fluorescence uptake was quantified. Mice were maintained on a diet of low-fluorescence chow (AIN76A; Harlan Teklad, Wisconsin) to minimize background noise. The FMT device was calibrated for use with sample standards of the E4G10-AF680 and anti-KLH-AF680 constructs in accordance with the manufacturer's guidelines. The values obtained from the measurements of these standards of the injected dose were entered into the TrueQuant software (VisEn Medical) to allow for quantification.
To determine the number of VE-cad epitopes in these tumors, we employed the data obtained from Hilmas and Gillette $^{49}$ that reported a morphometric analyses of tumor microvasculature during growth. Their data described changes in the tumor vascular volume, vessel diameter, mean vessel length, and surface area per unit volume of tumor tissue. Further, it was assumed that a VE cell has an area $^{50}$ of $1 \mathrm{E}-3 \mathrm{~mm}^{2}(0.141 \mathrm{~mm} \times 0.007 \mathrm{~mm})$ and that there were 1E9 cells per gram of tumor. The data of Hilmas and Gillette $^{49}$ reported that a $500 \mathrm{~mm}^{3}$ tumor had a vascular surface area per tumor volume of $13 \mathrm{~mm}^{2} / \mathrm{mm}^{3}$ and as the tumor volume increased (up to $1,500 \mathrm{~mm}^{3}$ ), the ratio of vascular surface area per tumor volume decreased and leveled at $12 \mathrm{~mm}^{2} / \mathrm{mm}^{3}$.

\section{RIT study to target and irradiate the tumor vasculature (survival and tumor regression)} A RIT study was performed in the LS174T xenograft tumor model with SWCNT-([225Ac]DOTA)(E4G10) vs appropriate controls. Briefly, tumor cells were xenografted 13 days before treatment (the mean \pm standard deviation tumor volumes for the animals in this study were $179 \pm 112 \mathrm{~mm}^{3}$ at the time RIT commenced). Mice were randomly separated into 4 groups before treatment, and all mice received a single IV dose of drug (or vehicle control) via the retro-orbital sinus except one mouse in group 1 that received a single intraperitoneal injection to investigate tumor targeting by that administration route. Group 1 mice $(\mathrm{n}=6)$ each received a single dose of the high $\mathrm{SA}=851 \mathrm{GBq} / \mathrm{g}$ SWCNT $(23 \mathrm{Ci} / \mathrm{g})$ Construct I containing $16.1 \mathrm{kBq}(435 \mathrm{nCi}){ }^{225} \mathrm{Ac}, 19 \mathrm{ng}$ SWCNT, and $29 \mathrm{ng}$ E4G10. Group 2 mice $(n=5)$ each received a single dose of the high $\mathrm{SA}=851 \mathrm{GBq} / \mathrm{g}$ SWCNT $(23 \mathrm{Ci} / \mathrm{g})$ isotype control Construct I containing $15.2 \mathrm{kBq}(410 \mathrm{nCi}){ }^{225} \mathrm{Ac}, 18 \mathrm{ng}$ SWCNT, and $27 \mathrm{ng}$ anti-KLH. Group 3 mice $(n=5)$ each received a single dose of the low SA $=1.9 \mathrm{GBq} / \mathrm{g}$ SWCNT $(0.05 \mathrm{Ci} / \mathrm{g})$ Construct I containing $0.037 \mathrm{kBq}(1 \mathrm{nCi}){ }^{225} \mathrm{Ac}, 19 \mathrm{ng}$ SWCNT, and $29 \mathrm{ng}$ E4G10. Group 4 mice $(n=4)$ each received a single dose of normal saline and served as a growth control. Mice were observed daily and tumor volumes measured and recorded. The tumor volumes were assessed using calipers to measure the diameters and the volume was calculated as $\mathrm{V}=a \times b^{2} \times 0.52$, where $a$ is the longest diameter and $b$ is the shortest diameter. When tumor volumes reached $1,000 \mathrm{~mm}^{3}$ or greater, mice were euthanized. Survival was analyzed as a function of time from treatment using Kaplan-Meier analysis.

\section{RII study of tumor vasculature}

A RII study was performed in the LS174T xenograft tumor model with SWCNT-([ $\left.\left.{ }^{89} \mathrm{Zr}\right] \mathrm{DFO}\right)(\mathrm{E} 4 \mathrm{G} 10)$ vs appropriate 
controls. Briefly, tumor cells were xenografted 13 days before treatment (the mean \pm standard deviation tumor volumes for the animals in this study were $558 \pm 413 \mathrm{~mm}^{3}$ at the time RII commenced). Mice were randomly separated into 3 groups before treatment, and all mice received a single IV dose of drug via the lateral tail vein. All the SWCNT- $\left(\left[{ }^{89} \mathrm{Zr}\right] \mathrm{DFO}\right)(\mathrm{IgG})$ constructs were labeled to high SA $(592 \mathrm{GBq} / \mathrm{g}$ SWCNT [16 $\mathrm{Ci} / \mathrm{g}])$. Group 1 mice $(\mathrm{n}=4)$ received a single dose of Construct II containing $4.18 \mathrm{MBq}(0.113 \mathrm{mCi}){ }^{89} \mathrm{Zr}, 7,000 \mathrm{ng} \mathrm{SWCNT}$, and 15,700 ng E4G10. Group 2 mice $(n=3)$ received a single IV $0.8 \mathrm{mg}$ dose of unlabeled E4G10 (50-fold excess relative to the construct-associated E4G10) 30 minutes before the single dose of Construct II containing $4.18 \mathrm{MBq}^{89} \mathrm{Zr}, 7,000 \mathrm{ng}$ SWCNT, and 15,700 ng E4G10. This group served as a blocking control. Group 3 mice $(n=3)$ received a single dose of the isotype control Construct II containing $3.08 \mathrm{MBq}(0.083 \mathrm{mCi})$ ${ }^{89} \mathrm{Zr}, 5,200 \mathrm{ng}$ SWCNT, and 12,100 ng anti-KLH.

The PET study was performed with a microPET Focus ${ }^{\mathrm{TM}}$ 120 (CTI Molecular Imaging, Knoxville, TN, USA). Mice were maintained under $2 \%$ isoflurane/oxygen anesthesia during the scanning. Images were recorded at various time points between 0-96 hours after injection. The list-mode data were acquired for between 10 and 30 minutes using a $\gamma$-ray energy window of 350-750 keV and a coincidence timing window of $6 \mathrm{~ns}$. For all static images, scan time was adjusted to ensure a minimum of 20-million coincident events recorded. Data were sorted into 2-dimensional histograms by Fourier rebinning, and transverse images were reconstructed by filtered back-projection into a $128 \times 128 \times 63(0.72 \times 0.72 \times 1.3 \mathrm{~mm})$ matrix. The reconstructed spatial resolution for ${ }^{89} \mathrm{Zr}$ was $1.9 \mathrm{~mm}$ full width at half maximum at the center of the field of view. The image data were normalized to correct for nonuniformity of response of the PET, dead-time count losses, positron-branching ratio, and physical decay at the time of injection but no attenuation, scatter, or partial volume-averaging correction was applied. An empirically determined system calibration factor (in units of $[\mathrm{mCi} / \mathrm{mL}] /[\mathrm{cps} /$ voxel] $)$ for mice was used to convert voxel count rates to activity concentrations. The resulting image data were then normalized to the administered activity to parameterize images in terms of $\% \mathrm{ID} / \mathrm{g}$. Manually drawn 2-dimensional region of interest (ROI) or 3-dimensional VOI were used to determined the maximum and mean $\% \mathrm{ID} / \mathrm{g}$ (decay corrected to the time of injection) in various tissues. ${ }^{6}$ Images were analyzed by using ASIPro VM 5.0 software (Concorde Microsystems, Knoxville, TN, USA).

\section{Characterization of E4G 10 reactivity}

LS174T, Chinese hamster ovary $(\mathrm{CHO})$, and $\mathrm{CHO}$ cells that stably expressed human VE-cad were assessed for VE-cad expression by flow cytometry. Cells were stained with E4G10 plus a secondary goat anti-rat phycoerythrin IgG-conjugated antibody (R\&D Systems) and then analyzed by flow cytometry (FACSAria; Beckman Coulter). In addition, lysates from these cell lines were tested for VE-cad expression by Western blot analysis. The lysates were resolved on a $4 \%-12 \%$ NuPAGE Bis-Tris gel (Invitrogen) and transferred to a polyvinylidene difluoride membrane, and VE-cad was detected using E4G10 plus a goat anti-rat horseradish peroxidase IgG-conjugated antibody (R\&D Systems). In addition, glyceraldehyde 3-phosphate dehydrogenase (GAPDH) was included as a loading control and was measured to evaluate protein loading using an anti-GAPDH pAb (R\&D Systems).

\section{Data analyses}

Three-dimensional VOI analysis on PET images was accomplished with ASIPro VM 5.0 software (Concorde Microsystems). Statistical data were evaluated using Graphpad Prism 5.0 (Graphpad Software Inc, La Jolla, CA, USA). Analysis of NIR images used the VisEn FMT2500 instrument's TrueQuant software (VisEn Medical). Statistical comparison between 2 experimental groups was performed using a $t$ test (unpaired comparison); comparison of multiple groups was performed with the one-way analysis of variance using Bonferroni's multiple comparison post hoc analysis. All statistical comparisons were 2-sided, and the level of statistical significance was set at $P<0.05$.

\section{Results Construct syntheses and amplification of specific activity}

The SWCNT-(DOTA)(HNH) precursor to Construct I was assayed and found to contain $1 \mathrm{mmol}$ DOTA and $0.06 \mathrm{mmol}$ $\mathrm{HNH}$ per gram of SWCNT. This precursor was radiolabeled (reaction 1) with 5 different amounts of ${ }^{225} \mathrm{Ac}$ activity, which after SEC purification yielded 96\% radiochemically pure SWCNT-([225Ac]DOTA $)(\mathrm{HNH})$. The SA for the 5 reaction products was $2.15,4.07,12.1,108$, and $914 \mathrm{GBq} / \mathrm{g}(0.058,0.11$, $0.326,2.91$, and $24.7 \mathrm{Ci} / \mathrm{g}$, respectively). The 2 antibody components, E4G10-FB and the isotype control anti-KLH-FB, had 5-7 FB reactive groups appended per $\operatorname{IgG}$ (reaction 2). These $\mathrm{IgG}$ precursors were in turn reacted (reaction 3 ) in 5-fold excess (per $100 \mathrm{~nm}$ of SWCNT) with the SWCNT-([225 Ac]DOTA)(HNH) (0.058 and $24.7 \mathrm{Ci} / \mathrm{g}$ ) precursors to yield the RIT Construct I at two different SA and the nontargeting high-SA isotype control Construct I. Approximately $3 \mathrm{IgG}$ per construct were appended per SWCNT. The starting amount of radioactivity used in the reaction is plotted vs the resultant SA (Figure 2). 
The preclinical radiolabeling data for ${ }^{225} \mathrm{Ac}-\mathrm{E} 4 \mathrm{G} 10$ yielded SA of $6.7 \pm 4.4 \mathrm{GBq} / \mathrm{g}(0.18 \pm 0.12 \mathrm{Ci} / \mathrm{g})$ with RCP of $96.7 \% \pm 2.6 \%$. The radiolabeled clinical $\mathrm{IgG},{ }^{225} \mathrm{Ac}-$ lintuzumab, yielded SA of $6.7 \pm 1.9 \mathrm{GBq} / \mathrm{g}(0.18 \pm 0.05$ $\mathrm{Ci} / \mathrm{g}$ ) with $\mathrm{RCP}$ of $97.2 \% \pm 2.5 \%$. A comparison of the SWCNT-(DOTA)(HNH) precursor and the IgG construct labeling results demonstrates that the increased amount of DOTA per SWCNT yields almost a 2-log amplification of SA vs the IgG-DOTA constructs (Figure 2).

The $N$-succDFO product was obtained in $62 \%$ yield. High resolution mass spectrometry confirmed the product identity (HRMS-ES ${ }^{+}$Calculated for $\left[\mathrm{C}_{29} \mathrm{H}_{52} \mathrm{~N}_{6} \mathrm{O}_{11}+\mathrm{H}^{+}\right]=661.3772$; found $661.3760\left(\left[\mathrm{M}+\mathrm{H}^{+}\right]=100 \%\right)$.

The SWCNT-(DFO)(FB) precursor to Construct II was assayed and found to contain $0.4 \mathrm{mmol}$ DFO and $0.3 \mathrm{mmol}$ FB per gram of SWCNT. This precursor was radiolabeled with ${ }^{89} \mathrm{Zr}$ activity, which after SEC purification yielded $97 \%$ radiochemically pure SWCNT-([ $\left.\left.{ }^{89} \mathrm{Zr}\right] \mathrm{DFO}\right)(\mathrm{FB})$ (reaction 4). The SA was $592 \mathrm{GBq} / \mathrm{g}(16 \mathrm{Ci} / \mathrm{g})$. To assemble Construct II, $\sim 11$ $\mathrm{HNH}$ reactive groups were appended per IgG to yield E4G10$\mathrm{HNH}$ and the isotype control anti-KLH-HNH (reaction 5). These antibody precursors were in turn reacted with the
SWCNT-([ $\left.\left.{ }^{89} \mathrm{Zr}\right] \mathrm{DFO}\right)(\mathrm{FB})$ precursor in 10 -fold excess (to SWCNT) to yield the RII Construct II and the nontargeting isotype control Construct II (reaction 6). Approximately 3 IgG per construct were appended per SWCNT.

\section{PK profile of E4G I 0 and the number of VE-cad monomer epitopes per cell}

The E4G10-AF680 and anti-KLH-AF680 constructs prepared for the FMT tumor NIR imaging and PK studies were prepared in $75 \%$ and $51 \%$ yield, respectively. Spectrophotometric analysis revealed that there were 5.5 AF680 appended per E4G10 and 10.2 AF680 per anti-KLH isotype control. Both constructs were $99 \%$ pure as determined by HPLC analysis. The amount of dye that accumulated in each tumor was imaged and measured on days 1, 2, 3, 5, 6, and 7 by FMT imaging. NIR FMT images of 2 representative mice demonstrate the differential targeting of the VE-cad epitope in the LS174T tumor vessels with E4G10-AF680 vs a similarly prepared isotype anti-KLH-AF680 nontargeting control construct 7 days after injection (Figure 3). There was $1.2 \pm 1$ pmol E4G10-AF680 (mean \pm standard deviation) vs $0.04 \pm 0.06 \mathrm{pmol}$ anti-KLH-AF680 per group

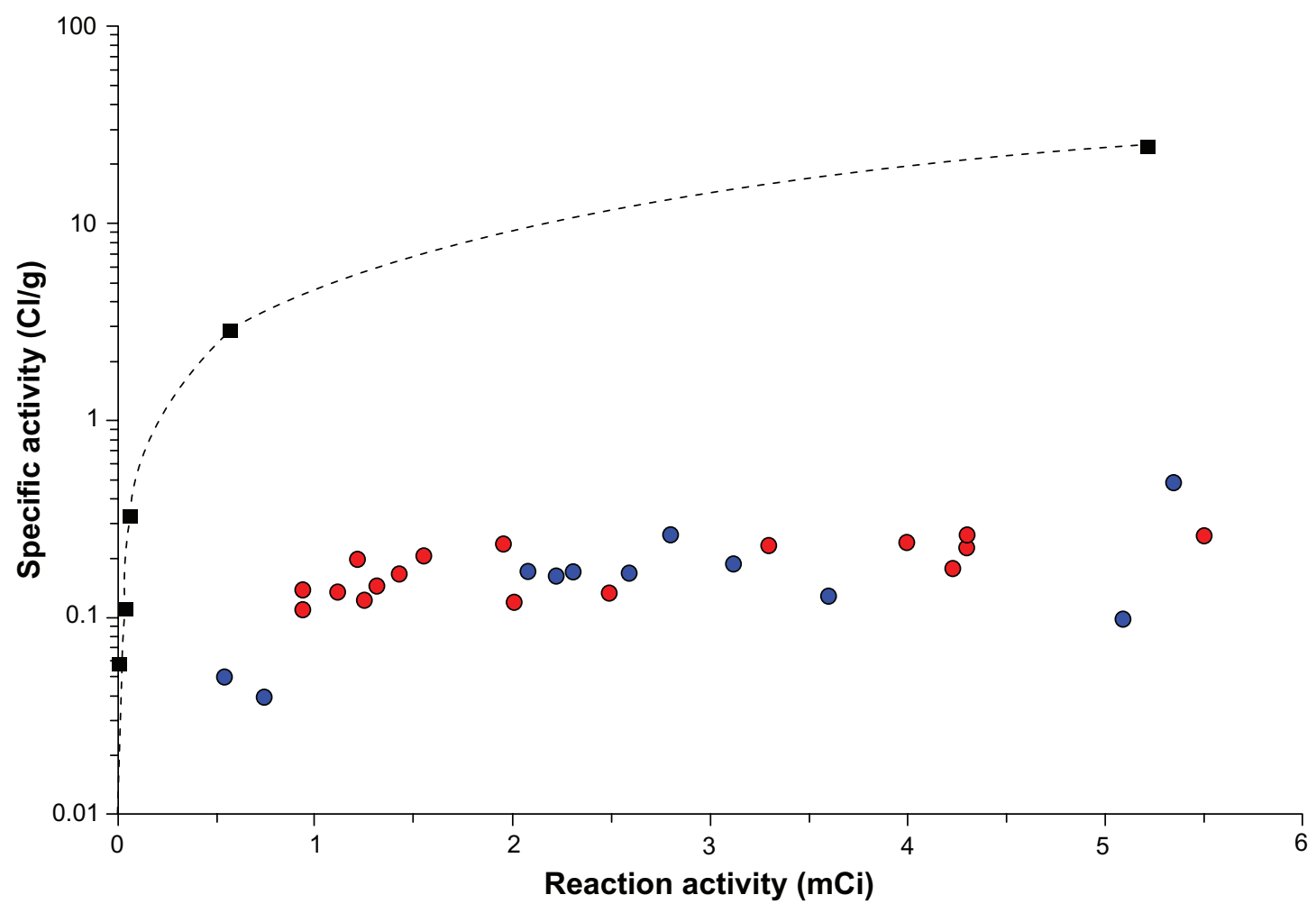

Figure $2 \mathrm{~A}$ plot of the starting ${ }^{225} \mathrm{Ac}$ activity used to radiolabel vs the final specific activity. The multiple copies of DOTA chelate covalently appended to the SWCNT scaffold (filled black squares) permit amplification of the amount of radioactivity that can be loaded onto the targeting construct relative to 2 different lgG-DOTA constructs (lintuzumab [filled red circles] and E4G 10 [filled blue circles]). The nonlinear regression fitted curve (dashed black line) is shown for the SWCNT-DOTA labeling data. Abbreviations: ${ }^{225} \mathrm{Ac}$, actinium-225; DOTA, I,4,7, I0-tetraazacyclododecane-I,4,7, I0-tetraacetic acid; SWCNT, single wall carbon nanotube; IgG, immunoglobulin G. 


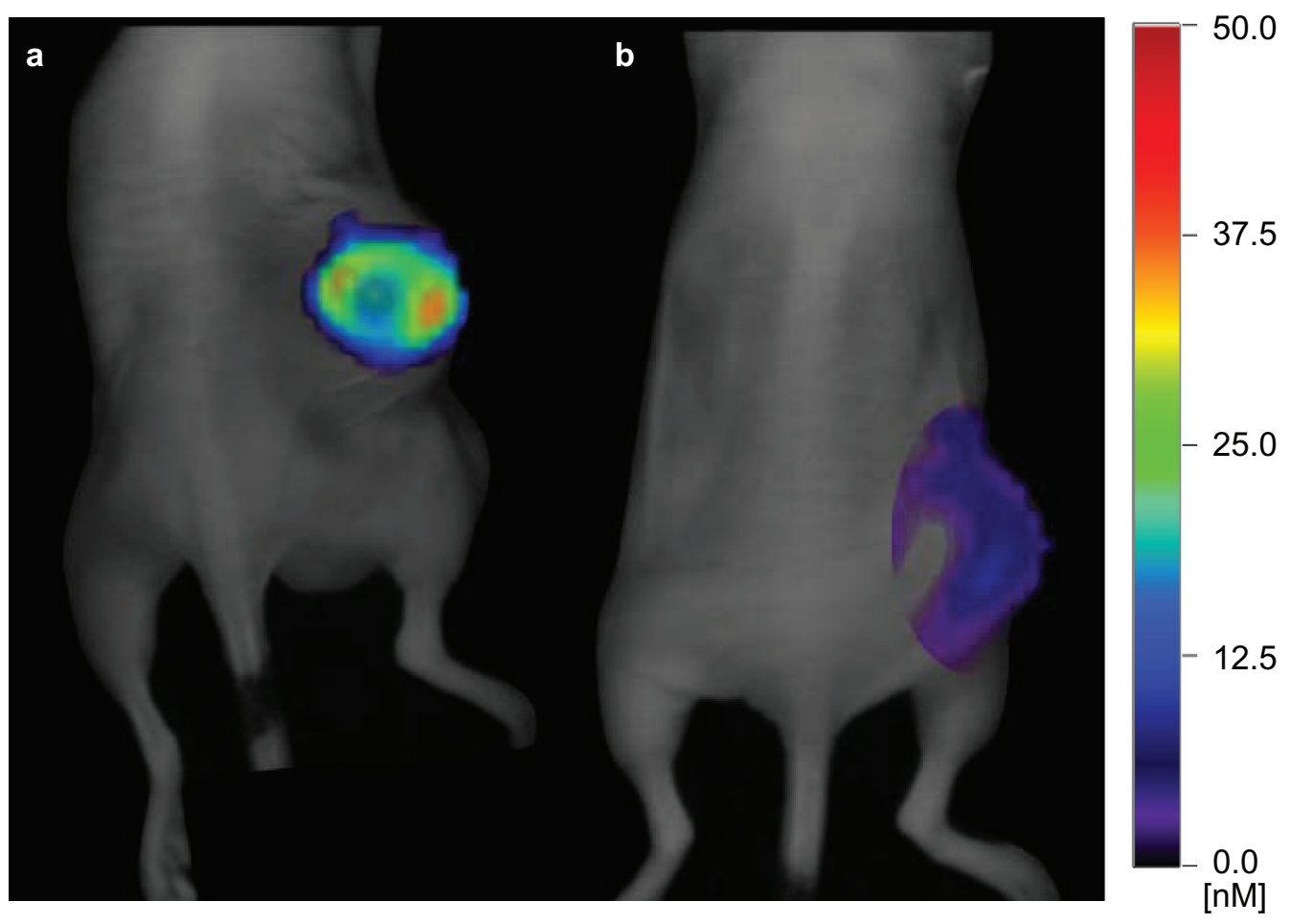

Figure 3 Near-infrared three-dimensional fluorescent-mediated tomographic images of 2 representative mice showing the targeting of the monomeric VE-cad epitope in the subcutaneous LSI74T tumor with A) E4GI0-AF680 vs B) anti-KLH-AF680, a similarly prepared nontargeting isotype control construct, 7 days after injection. Abbreviations: VE-cad, vascular endothelial-cadherin; anti-KLH, anti-keyhole limpet hemocyanin.

( $n=5$ mice per group) on day 7 representing a 30 -fold excess of signal-to-noise at this time.

A kinetic analysis of this data yielded the concentration of IgG-AF680 per tumor per day (Figure 4), which demonstrated a blood compartment clearance time of $\sim 3$ days. The tumor volumes (mean \pm standard deviation) of the E4G10AF680 group were $1,208 \pm 444 \mathrm{~mm}^{3}(\mathrm{n}=5)$, and the antiKLH-AF680 group had tumor volumes of 1,022 $\pm 667 \mathrm{~mm}^{3}$ $(n=5)$ on the second day of NIR FMT imaging study. This PK data were also used to calculate an estimate of the number of VE-cad per VE cell. In the E4G10-AF680 group, the mean tumor volume was $1,208 \mathrm{~mm}^{3}$, and $3.2 \pm 0.08$ pmol of E4G10 was accumulated after the blood compartment clearance. Using data from Hilmas and Gillette ${ }^{49}$ along with the aforementioned assumptions, there were 1.44E7 VE cells in the tumor with 1.33E5 VE-cad epitopes per VE cell. (The isotype control group that received the anti-KLH-AF680 had $0.27 \pm 0.25$ pmol of antibody in the tumor.)

\section{RIT targeted to the tumor vessels improved median survival and tumor regression}

A single administration of the high SA Construct I to the RIT group 1 mice significantly improved the median survival relative to the RIT group 4 mice (the growth controls; 26 days vs 12.5 days; $P=0.0334$ ). RIT group 2 mice received the high SA isotype control Construct I and RIT group 3 mice received the low SA Construct I and had median survival times of 13 and 14 days, respectively. The Kaplan-Meier survival plot and the plot of the change in tumor volumes from time of treatment showed the benefit of a single dose, high SA Construct I relative to controls (Figure 5). It was observed that on day 10 after treatment, there was a noticeable transient decrease in tumor volume in RIT group 1 mice compared with other groups. Photographic images (Figure 6) of a representative mouse from RIT groups 1 and 3 are shown at day 10 from treatment to illustrate the therapeutic effect of the high SA drug construct control vs the low SA drug construct control. The tumor volume was significantly less in the RIT group 1 mouse with a lesion scar in the center of the tumor area.

\section{RII of tumor vasculature}

A single IV administration of Construct II to the RII group 1 mice via the lateral tail vein showed rapid accumulation by PET ROI analysis of signal in the tumor $(\sim 0.36 \% \mathrm{ID} / \mathrm{g}$ at 24 hours after injection) (Figure 7A). RII group 2 mice $(\mathrm{n}=3)$ received a single IV $0.8 \mathrm{mg}$ dose of unlabeled E4G10 


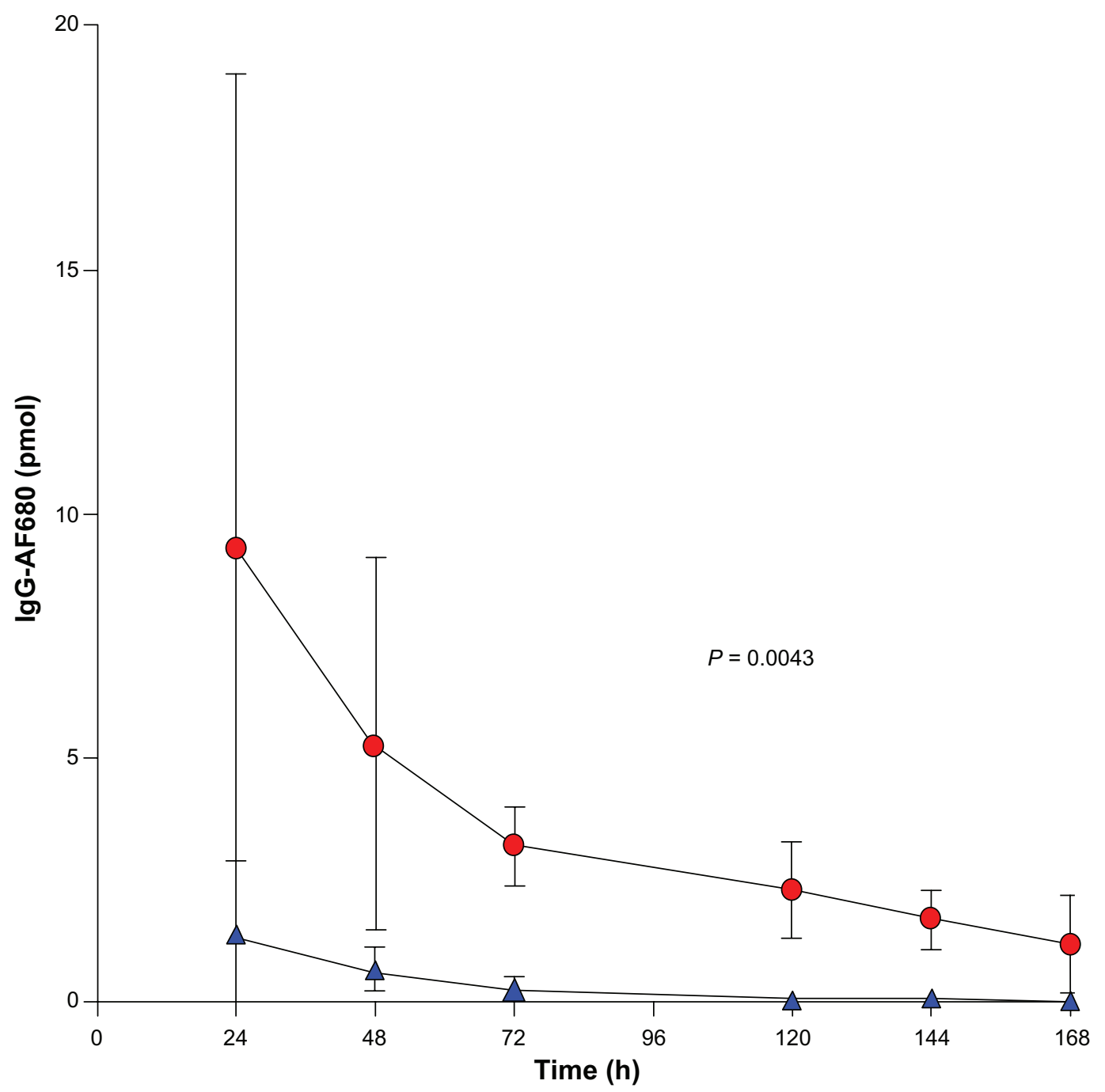

Figure 4 Near-infrared three-dimensional fluorescent-mediated tomographic signal (normalized for moles of AF680 dye per lgG) in the LSI 74T tumor as a function of time after injection. E4GI0-AF680 (red circles) vs a similarly prepared isotype anti-KLH-AF680 (blue triangles).

Abbreviations: IgG, immunoglobulin G; anti-KLH, anti-keyhole limpet hemocyanin.

(50-fold excess relative to the construct-associated E4G10) 30 minutes prior to a single dose of Construct II and did not show accumulation of signal in the tumor $(\sim 0.24 \% \mathrm{ID} / \mathrm{g}$ at 24 hours after injection) (Figure 7B). RII group 3 mice $(n=3)$ received a single dose of the isotype control Construct II and did not show accumulation of signal in the tumor ( $\sim .18 \% \mathrm{ID} / \mathrm{g}$ at 24 hours after injection) (Figure $7 \mathrm{C}$ ). Other imaging data (Figure 8A) was taken from dynamic PET measurements in the first hour after administration which showed clearly the rapid blood compartment clearance $\left(t_{1 / 2}=15\right.$ minutes $)$. The tumor accumulation in a representative RII group 1 mouse showed rapid and persistent accumulation of drug, whereas a representative RII group 3 control mouse demonstrated decrease of tumor-associated activity in the first 5 minutes that leveled off and appeared as noise. Further PET ROI data (Figure 8B) from a representative mouse from RII group 1 was plotted as a function of time at $1,4,24$, and 96 hours and showed a tumor-to-muscle ratio of $1.61,1.98,2.95$, and 5.08, respectively. The tumor-to-muscle ratios were highest at 96 hours, but reasonable contrast was apparent between 4 and 24 hours. This demonstrated a significant improvement over the E4G10-alone imaging agent that required $\sim 3-4$ days for the blood compartment activity to clear.

\section{Discussion}

The concurrent processes of angiogenesis and tumor cell proliferation are keys to tumor growth and dissemination and are interrelated by a paracrine effect. ${ }^{51}$ Endothelial cells will expand to produce a tortuous network of vessels that supplies required nutrients, oxygen, cytokines, and chemokines to tumor cells. Disrupting and damaging the 


\section{A}

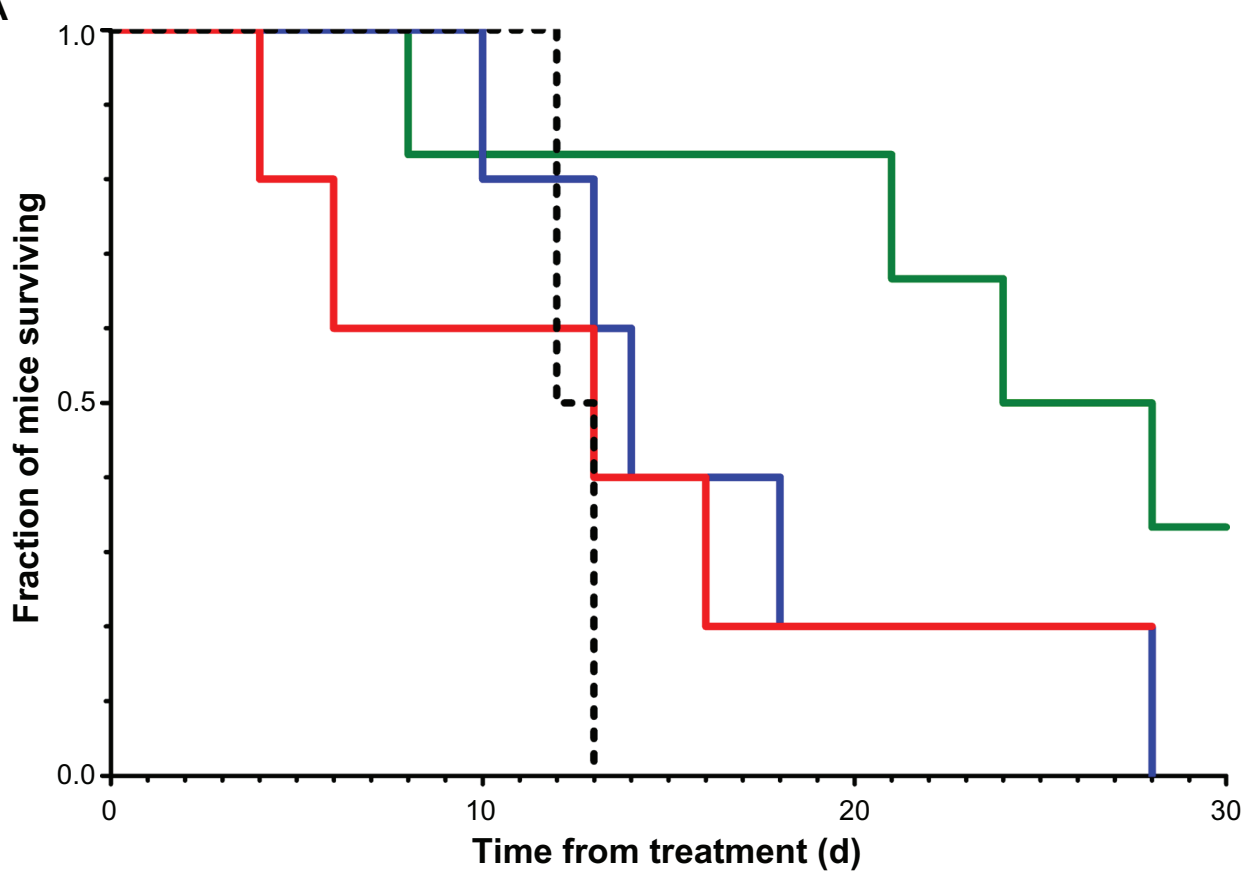

B

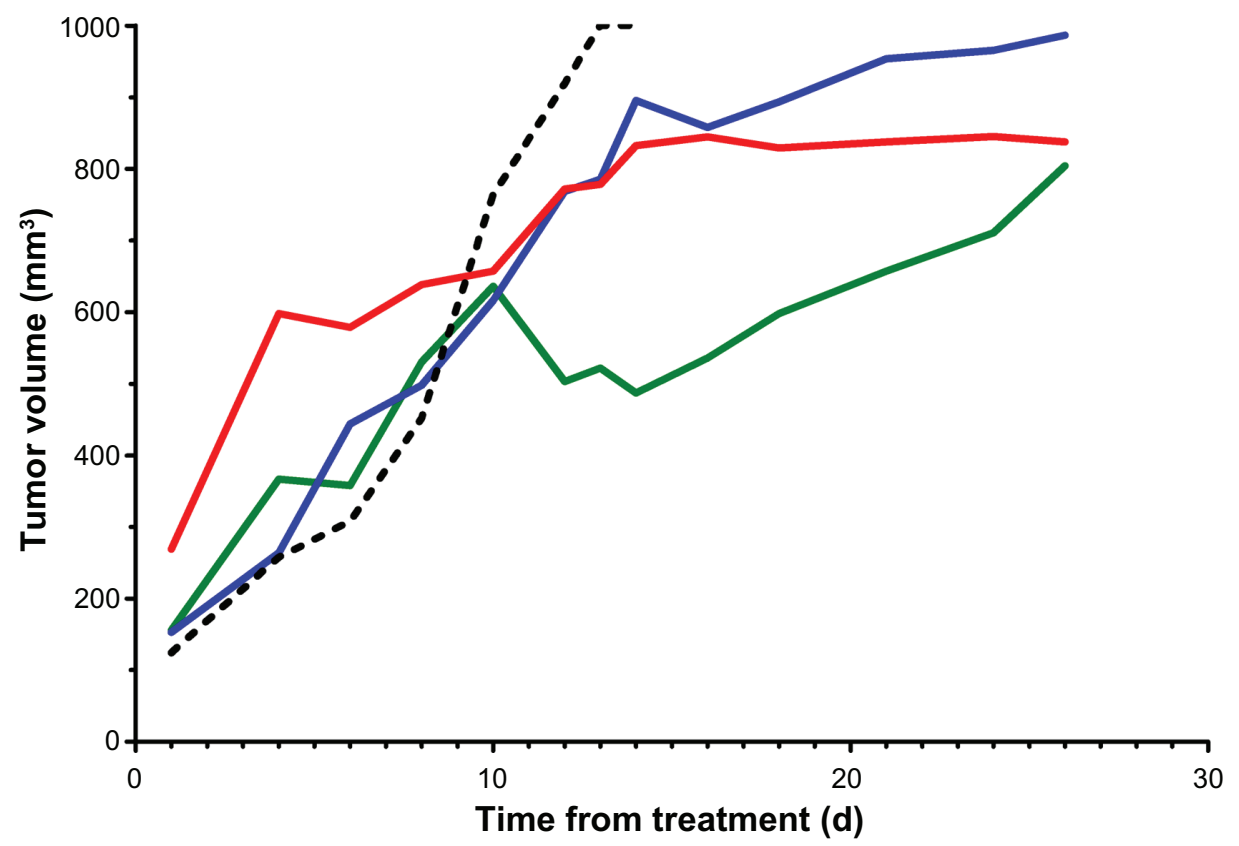

Figure 5 Kaplan-Meier survival plot of the fraction of LSI74T-xenografted mice surviving vs time following treatment with A) high SA SWCNT-([225Ac]DOTA)(E4G I0) (solid green line); high SA SWCNT-([225Ac]DOTA)(anti-KLH) (solid red line); low SA SWCNT-([225Ac]DOTA)(E4G I0) (solid blue line); and untreated growth control (dashed black line). B) Mean tumor volumes for each treatment group as a function of time from treatment (Note, the line colors and styles correspond to the data in panel A).

Abbreviations: SA, specific activity; SWCNT, single wall carbon nanotube; ${ }^{225}$ Ac, actinium-225; DOTA, I,4,7, 10-tetraazacyclododecane-I,4,7,I0-tetraacetic acid; anti-KLH, anti-keyhole limpet hemocyanin.

vascular endothelial architecture associated with tumor tissue have been recognized as a viable therapeutic strategy. ${ }^{51-57}$ Furthermore, imaging modalities that can specifically target the tumor vessels would be of value in diagnosing disease and following the progression or regression as a function of treatment. ${ }^{58,59}$
We hypothesized that novel synthetic structures based on hybrid molecules consisting of targeting biologics, radionuclides, and CNTs will have emergent anticancer properties. These molecular hybrids were designed to amplify the intrinsic targeting, binding, imaging, and therapeutic attributes of a drug construct and should, therefore, improve 


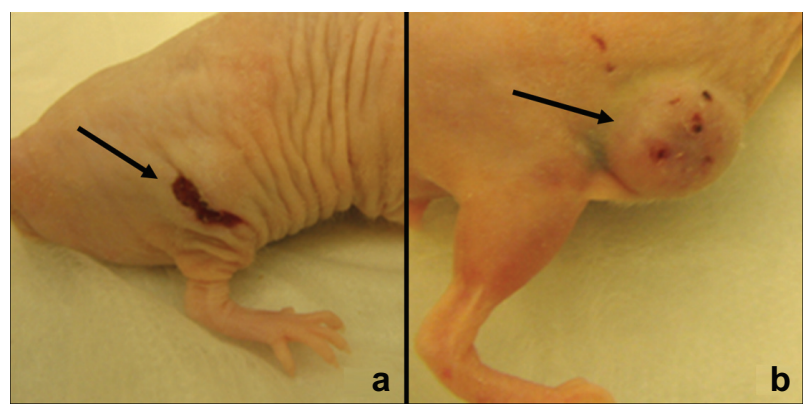

Figure 6 Two representative LSI74T-xenografted mice from the radioimmunotherapeutic study 10 days after treatment. A) A mouse treated with high SA SWCNT-([225Ac]DOTA)(E4GI0). B) A mouse treated with low SA SWCNT([225Ac]DOTA)(E4GI0).

Abbreviations: SA, specific activity; SWCNT, single wall carbon nanotube; ${ }^{225} \mathrm{Ac}$, actinium-225; DOTA, I,4,7, I0-tetraazacyclododecane-I,4,7,10-tetraacetic acid.

potency, specificity, and efficacy relative to current drugs. Irradiation of the vessels associated with tumor tissue was effected by specifically targeting the high LET alpha particle-emitting ${ }^{225} \mathrm{Ac}$ in high SA to the VE-cad epitope; however, imaging the tumor vessels was effected by specifically targeting the same epitope with the positron-emitting ${ }^{89} \mathrm{Zr}$ in high SA.

We previously demonstrated that an alpha particleemitting, vascular-targeting antibody construct, ${ }^{225} \mathrm{Ac}-\mathrm{E} 4 \mathrm{G} 10$, could specifically irradiate prostate carcinoma vascular endothelial cells ${ }^{27}$ and also their bone marrow-derived endothelial progenitors, ${ }^{28}$ delaying tumor growth and improving survival. We have also examined ${ }^{225} \mathrm{Ac}-\mathrm{E} 4 \mathrm{G} 10$ in vascular-targeting strategies to treat animal models of glioblastoma mutiforme ${ }^{25,26}$ and the colon carcinoma (LS174T) model of tumor vasculature. ${ }^{60}$ Others have also used vascular-targeting, alpha particle-emitting RIT approaches to treat animal models of disease ${ }^{61-64}$ or vascular/tumor epitope-targeting RII approaches to PET image tumor. ${ }^{65-67}$

Two particular SWCNT properties, the high aspect ratio and the periodic structure, have rendered this nanomaterial amenable to being simultaneously appended with multiple copies of reactive primary amines, radiometal-ion chelates (DOTA or DFO), and IgGs. By amplifying the number of chelates per SWCNT, we have demonstrated a 2-log increase of SA of radiolabeling of SWCNT-(DOTA) relative to IgG constructs. Each of these SWCNT molecules had 100 DOTA or DFO chelates appended per SWCNT. In contrast, an IgG might only accommodate 5-10 DOTA moieties per molecule before losing the ability to target and bind efficiently. ${ }^{68}$

The radiotherapeutic SWCNT constructs, labeled with ${ }^{225} \mathrm{Ac}$, were also functionalized with multiple copies of E4G10 antibody and used to treat LS174T tumors vs low SA control, nontargeting high SA isotype IgG control, and growth control. Survival of animals treated with high SA Construct I was doubled after only one treatment relative to the control groups and was significantly better than the growth controls. Tumor growth was also arrested and regressed in the high SA RIT group 1. The mice treated with the high SA, tumor vascular-targeting Construct I showed significant tumor regression while the low SA targeting analog did not control tumor growth. The image of the regressed tumor lesion was similar to the images obtained by Nilsson and Neri ${ }^{69}$ who targeted the delivery of tissue factor to the ED-B domain of fibronectin, a marker of angiogenesis, and mediated the infarction of solid tumors in mice.

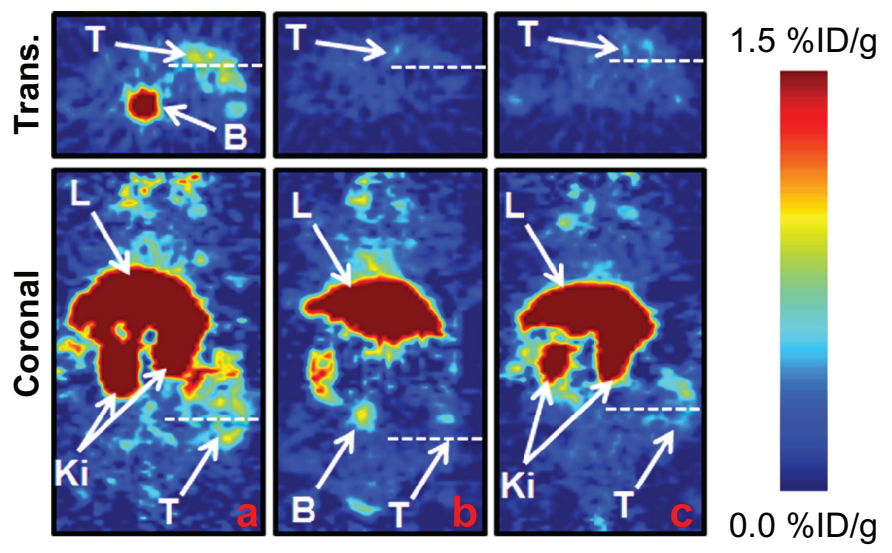

Figure 7 PET images of 3 representative subcutaneous LSI74T tumored mice that received an IV injection of A) SWCNT-([897r]DFO)(E4GI0); B) low SA ${ }^{89} \mathrm{Zr}$-DFOSWCNT-E4GIO (competitive inhibition or blocking control experiment); and C) nonspecific control construct SWCNT-([ $\left.\left.{ }^{99} \mathrm{Zr}\right] \mathrm{DFO}\right)($ anti-KLH) recorded at 24 hours after injection. The top panel is the transverse image and the bottom panel is the coronal image. The notations T, L, Ki, and B indicate the tumor, liver, kidneys, and bladder, respectively.

Abbreviations: PET, positron emission tomography; IV, intravenous; SWCNT, single wall carbon nanotube; ${ }^{89} \mathrm{Zr}$, zirconium-89; DFO, desferrioxamine B; SA, specific activity; anti-KLH, anti-keyhole limpet hemocyanin; Trans, transverse. 
The increased SA was also key to achieving a high signal-to-noise ratio for imaging purposes. We have utilized this increased sensitivity with indium-111 ( $\left.{ }^{111} \mathrm{In}\right)$ and ${ }^{86} \mathrm{Y}$ labeled SWCNT-(DOTA) constructs for PK studies. ${ }^{3-6}$ In addition, covalently SWCNT-appended IgG and peptides have conferred biological targeting and binding capabilities to this scaffold and bind to the specific antigen epitope in vitro and in vivo. ${ }^{3,5}$ We were able to improve the SA of the
${ }^{89} \mathrm{Zr}$-labeled RII Construct II $\sim 5$-fold relative to ${ }^{89} \mathrm{Zr}$-labeled IgG-only labeled constructs. ${ }^{30}$

Another key SWCNT property that was utilized extensively was the favorable PK profile that featured rapid blood compartment clearance. The RII Construct II targeted and bounded and then rapidly cleared the blood compartment and the muscle yielding excellent contrast for imaging. The targeting system also favored this profile as

A

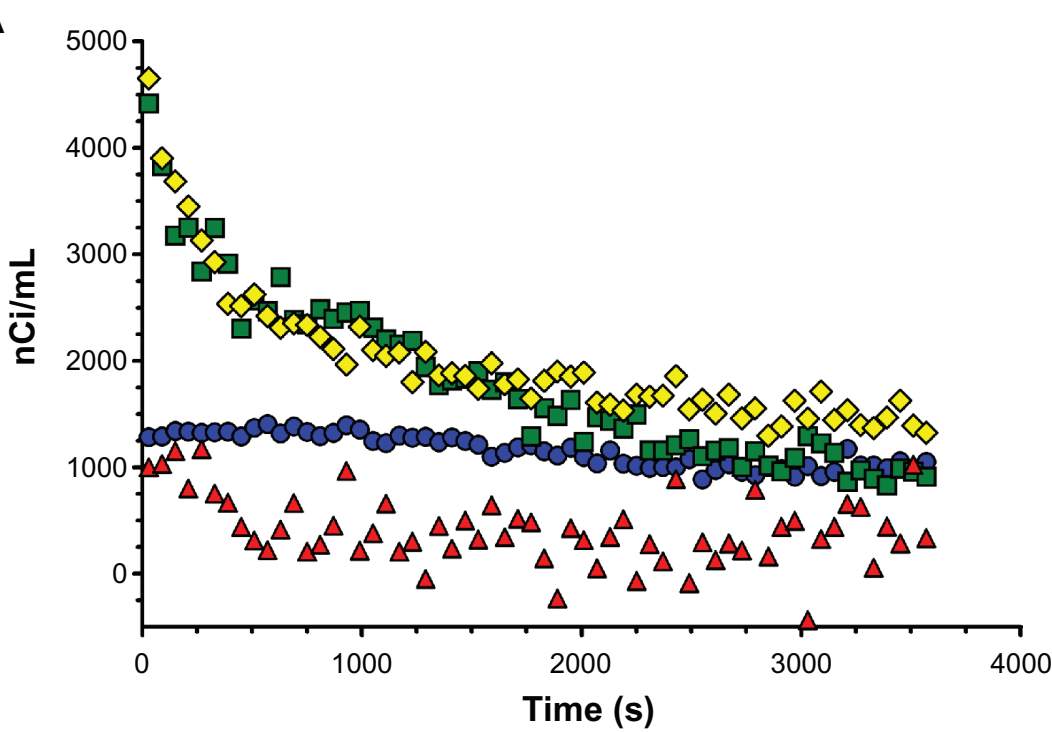

B

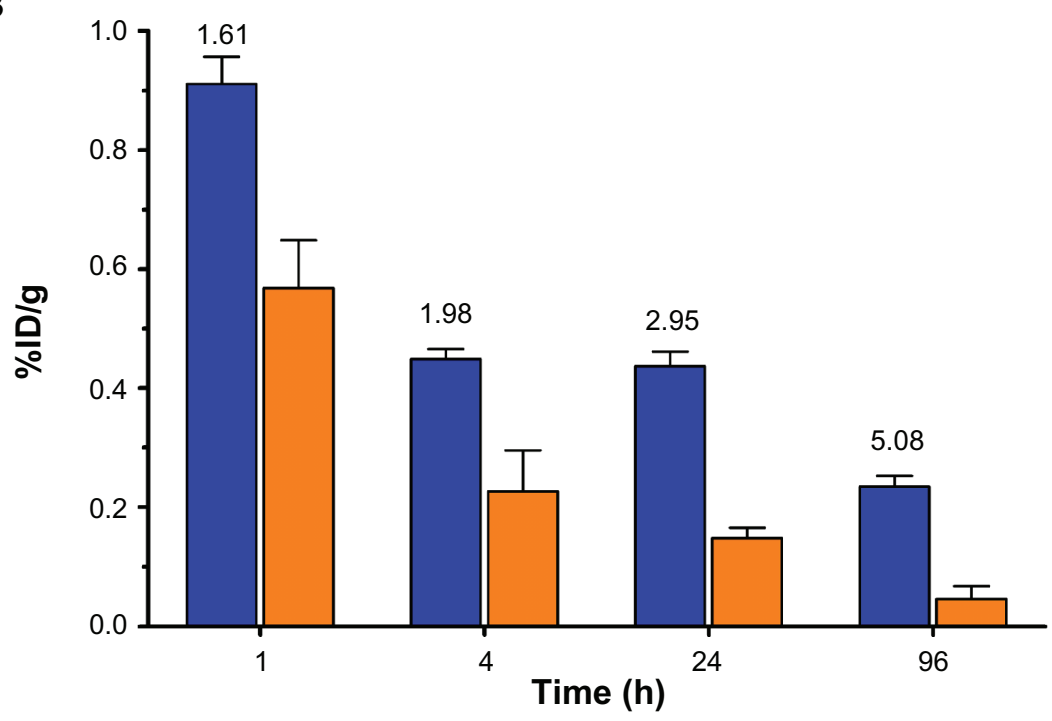

Figure 8 PET data showing tumor accumulation and corresponding blood and muscle clearance of the construct as a function of time. A) TAC from 2 representative LSI74T-xenografted-mice that were dynamically PET imaged immediately after IV administration of SWCNT-([ $\left.\left.{ }^{89} \mathrm{Zr}\right] \mathrm{DFO}\right)(\mathrm{E} 4 \mathrm{GIO})$ and SWCNT-([ $\left.\left.{ }^{89} \mathrm{Zr}\right] \mathrm{DFO}\right)$ (E4GI0) + excess unlabeled E4GIO (cold blocking control). Tumor accumulation (blue circles) and blood compartment clearance (green squares) were determined by ROI analysis for the mouse that received the dose of SWCNT-([ $\left.\left.{ }^{89} \mathrm{Zr}\right] \mathrm{DFO}\right)(\mathrm{E} 4 \mathrm{GI0})$. Similarly, tumor accumulation (red triangles) and blood compartment clearance (yellow diamonds) were determined by ROI analysis for the mouse that received the blocking dose of excess E4GIO and then the dose of SWCNT( $\left.\left[{ }^{89} \mathrm{Zr}\right] \mathrm{DFO}\right)(\mathrm{E} 4 \mathrm{GI}$ ) $)$ B) PET ROI data showing tumor (blue bars) and muscle (orange bars) accumulation (mean \pm standard deviation) as a function of time for a

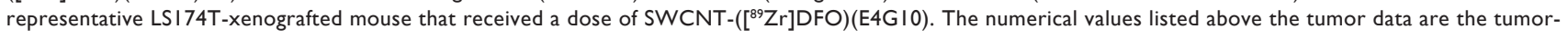
to-muscle ratios.

Abbreviations: PET, positron emission tomography; TAC, time activity curve; IV, intravenous; SWCNT, single wall carbon nanotube; ${ }^{89} \mathrm{Zr}$, zirconium-89; DFO, desferrioxamine $B$; ROI, region of interest. 
the murine VE-cad epitope is expressed in the vessel lumen and, therefore, is readily accessible to the CNT construct. The binding occurred rapidly, precluding any need to diffuse into the solid tumor to target and bind. All of these studies demonstrated that the administered constructs were safe and well tolerated.

The SWCNT-E4G10 construct was tumor vessel specific and targeted the murine VE-cad. E4G10 did not cross-react with the LS174T tumor cells in flow cytometric or Western blot analyses (Figure 9). Furthermore, the normal, resting vasculature no longer exposes this epitope to the E4G10 IgG for binding, ${ }^{9}$ thus sparing normal vessels. An illustration of this VE-cad targeting concept using IV delivered soluble, targeting, radiolabeled (for imaging or therapy) constructs in patients with tumor is presented in Figure 10. The construct rapidly accesses the tumor vasculature and then can specifically bind to the monomeric VE-cad that is expressed in the neovasculature but cannot bind to resting vasculature with tight cell-cell contacts at the adherens junctions.

This E4G10/VE-cad targeting system is unlike the arginine-glycine-aspartic acid (RGD)-based agents that target the $\alpha_{\mathrm{v}} \beta_{3}$ integrin, which is often expressed by both the tumor and the vascular network. The RGD $/ \alpha_{v} \beta_{3}$ integrin system lacks the vascular specificity that we designed into our constructs. Targeting studies of vascular endothelial growth factor (VEGF)-A that is expressed in the LS174T human xenograft model with bevacizumab were complicated not only by the relatively small numbers of copies of epitope per tumor cell (12E3) but also by the imaging artifact that was created by the lack of expression of human VEGF-A in a mouse model. ${ }^{66}$

The NIR FMT imaging data in vivo yielded an estimate of the number of VE-cad expressed per vascular endothelial cell. Using the measured values of the moles of E4G10 (3.2 pmol) per tumor $\left(1,208 \mathrm{~mm}^{3}\right)$ and published vessel area values per tumor volume ${ }^{49}$ and VE cell area $\left(1 \mathrm{E}-3 \mathrm{~mm}^{2}\right),{ }^{50}$ there were $1.4 \mathrm{E} 7 \mathrm{VE}$ cells in the tumor with 1.3E5 VE-cad epitopes per VE cell. The VE-cad epitope was not expressed by the LS174T tumor and is a murine protein in the vessels of a mouse model. Baumgartner and Drenckhahn ${ }^{70}$ reported 6E6 VE-cad dimers (12E6 VEcad monomers) for immortalized mouse microvascular endothelial cells (MyEND) as determined in vitro using affinity chromatography and trypsinization. Our value was 90-fold lower than their value; however, it might be safely assumed that most of the vascular endothelial cells in our tumor were not newly formed angiogenic cells, and thus, the epitope was hidden. Since our value was based on total vascular endothelial cells, then if only $10 \%$ of the vascular endothelial cells in the tumor were newly formed or had irregularly or poorly connected adherens junctions,

A

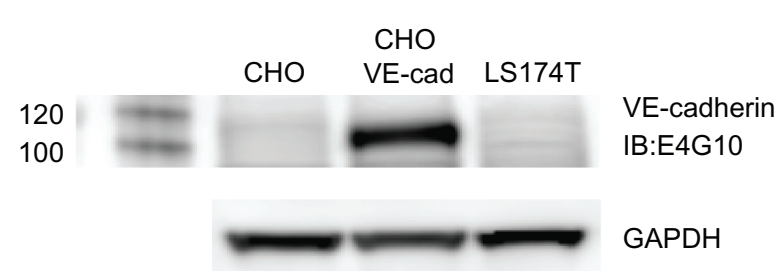

B
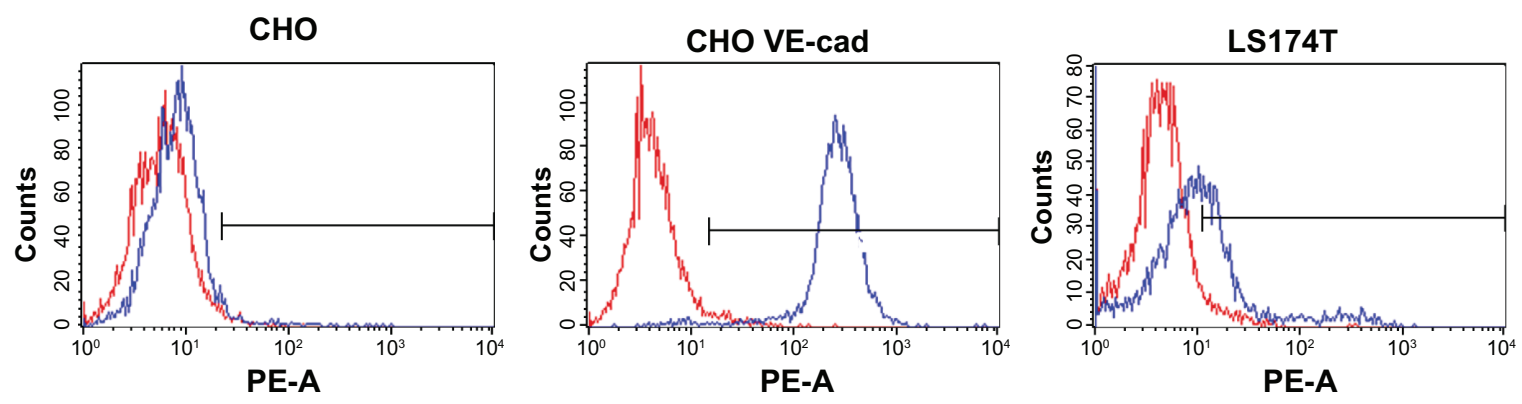

EAG10 + GAR-PE and Isotype + GAR-PE

Figure 9 Characterization of the E4GIO antibody. A) Western blot analysis of E4GIO binding to cell lysates from the (CHO), VE-cad-transfected CHO, and LSI74T cells. GAPDH was included as a loading control. B) Flow cytometric analysis showed the binding characteristics of E4GIO with the CHO, VE-cad-transfected CHO, and LSI74T cells. The $\lg \mathrm{G}$ isotype control was the anti-KLH antibody. The secondary lgG was a goat anti-rat phycoerythrin lgG.

Abbreviations: CHO, Chinese hamster ovary; VE-cad, vascular endothelial-cadherin; GAPDH, glyceraldehyde 3-phosphate dehydrogenase; IgG, immunoglobulin G; anti$\mathrm{KLH}$, anti-keyhole limpet hemocyanin. 


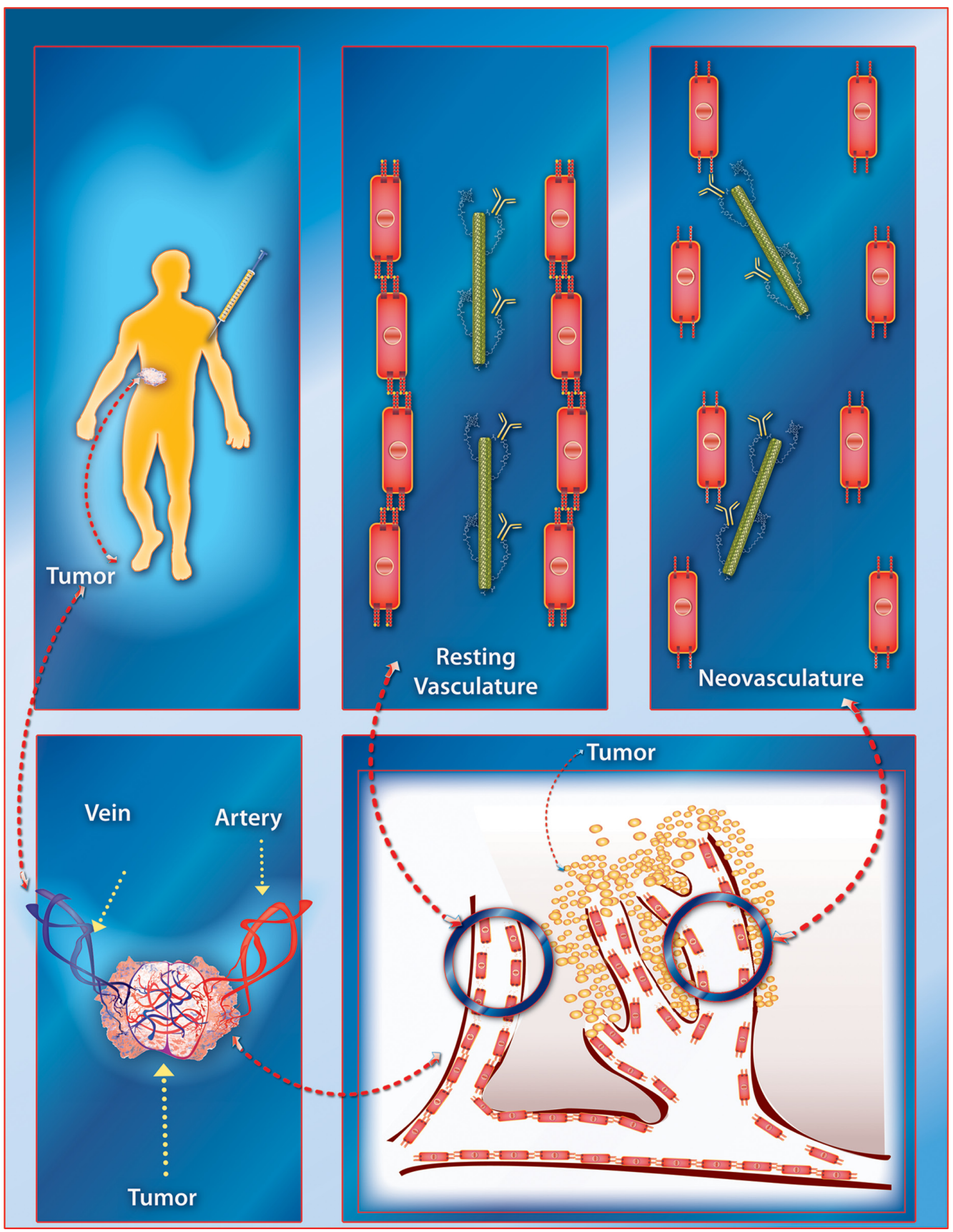

Figure 10 A graphical illustration of the tumor vascular-targeting concept using the carbon nanotube constructs. The soluble, covalently functionalized, and radiolabeled constructs are delivered intravenously to the patient with tumor. The construct rapidly accesses the tumor vasculature and then can specifically bind to the monomeric VE-cad that is expressed in the neovasculature but cannot bind to resting vasculature with tight cell-cell contacts at the adherens junctions. (Note, Figures are not drawn to scale.)

then our estimate of the number of epitopes per cell would increase 10-fold (1.3E6 VE-cad epitopes per VE cell). If the number of newly formed VE cells was only $1 \%$ of the total VE cell population in the tumor, then the value would increase 100-fold (1.3E7 VE-cad epitopes per VE cell). The latter assumption yielded a better correlation with the Baumgartner data.

\section{Conclusion}

SWCNT constructs were designed, constructed, and used to deliver therapeutic and imaging radionuclide cargoes specifically to the vessels of a solid tumor using a target on VE-cad found only on new vascular endothelium. The goal was to target the neovessels and irregular vessels in a tumor with these novel nanoconstructs and image 
accumulation and evaluate the therapeutic anti-angiogenic effects. The construct design incorporated 100-fold amplified cargo delivery (relative to the gold standard for targeted therapy - IgG) and was built to be multifunctional and thus had therapeutic or imaging cargo, as well as targeting capability conferred by the appended IgG. This proof of concept design resulted in a construct with therapeutic efficacy, good image contrast, and specificity for the target. This amplified SA may prove important in delivering potent enough therapy and sensitive enough diagnostic signals simultaneously to the tumor. Our data also provided support of the use of nanomaterials in vascular-targeting strategies. These SWCNT construct doses were well tolerated and safe in these animal models. The number of VE-cad epitopes per tumor was measured and extrapolated to estimate a number of bound VE-cad epitopes per cell. These latter results along with the PK profile will be of use in designing more optimized therapeutic and imaging studies with these constructs. Moving forward, it is anticipated that a single construct could be designed to incorporate both the imaging and therapeutic cargoes onto the same platform. Furthermore, because the construct targets an epitope expressed by the tumor vascular network, a single agent could be employed to image or treat a variety of different tumors.

\section{Acknowledgments/disclosure}

Funded in part by the National Institutes of Health grants R21 CA128406, R01 CA55349, R25T CA096945, R24 CA83084, P30 CA08748, P01 CA33049; the Memorial Sloan-Kettering Brain Tumor Center; the Memorial SloanKettering Experimental Therapeutics Center; the Geoffrey Beene Cancer Research Center of Memorial Sloan-Kettering Cancer Center; and the Office of Science (BER), US Department of Energy (Award DE-SC0002456). We would also like to thank Medactinium, Inc for the ${ }^{225} \mathrm{Ac}$; ImClone Systems (a wholly-owned subsidiary of Eli Lilly and Company) for the E4G10 antibody; and Amy Carol McDevitt for the graphic illustration and figure. Conflict of interest statement: David A Scheinberg is a consultant for Enscyce; Michael R McDevitt was a consultant for Medactinium; and Chad May was employed by ImClone Systems at the time of this study.

\section{References}

1. Scheinberg DA, Villa CH, Escorcia FE, McDevitt MR. Conscripts of the infinite armada: systemic cancer therapy using nanomaterials. Nat Rev Clin Oncol. 2010;7(5):266-276.
2. Kostarelos K, Bianco A, Prato M. Promises, facts and challenges for carbon nanotubes in imaging and therapeutics. Nat Nanotechnol. 2009;4(10):627-633.

3. McDevitt MR, Chattopadhyay D, Kappel BJ, et al. Tumor targeting with antibody-functionalized, radiolabeled carbon nanotubes. J Nucl Med. 2007:48(7);1180-1189.

4. McDevitt MR, Chattopadhyay D, Jaggi JS, et al. PET Imaging of soluble yttrium-86-labeled carbon nanotubes in mice. PLoS One. 2007; 2(9):e907.

5. Villa CH, McDevitt MR, Escorcia FE, et al. Synthesis and biodistribution of oligonucleotide-functionalized, tumor-targetable carbon nanotubes. Nano Lett. 2008;8(12):4221-4228.

6. Ruggiero A, Villa $\mathrm{CH}$, Bander E, et al. Paradoxical glomerular filtration of carbon nanotubes. Proc Natl Acad Sci U S A. 2010; 107(27): 12369-12374

7. Fox ME, Szoka FC, Frechet JMJ. Soluble polymer carriers for the treatment of cancer: the importance of molecular architecture. Acc Chem Res. 2009;42(8):1141-1151.

8. Corada M, Liao F, Lindgren M, et al. Monoclonal antibodies directed to different regions of vascular endothelial cadherin extracellular domain affect adhesion and clustering of the protein and modulate endothelial permeability. Blood. 2001;97(6):1679-1684.

9. Liao F, Doody JF, Overholser J, et al. Selective targeting of angiogenic tumor vasculature by vascular endothelial-cadherin antibody inhibits tumor growth without affecting vascular permeability. Cancer Res. 2002;62(9):2567-2575.

10. Corada M, Zanetta L, Orsenigo F, et al. A monoclonal antibody to vascular endothelial-cadherin inhibits tumor angiogenesis without side effects on endothelial permeability. Blood. 2002;100(3):905-911.

11. May C, Doody JF, Abdullah R, et al. Identification of a transiently exposed VE-cadherin epitope that allows for specific targeting of an antibody to the tumor neovasculature. Blood. 2005;105(11): 4337-4344.

12. Lamszus K, Brockmann MA, Eckerich C, et al. Inhibition of glioblastoma angiogenesis and invasion by combined treatments directed against vascular endothelial growth factor receptor-2, epidermal growth factor receptor, and vascular endothelial-cadherin. Clin Cancer Res. 2005; 11(13):4934-4940.

13. McDevitt MR, Ma D, Lai LT, et al. Tumor therapy with targeted atomic nano-generators. Science. 2001;294(5546):1537-1540.

14. Borchardt PE, Yuan RR, Miederer M, McDevitt MR, Scheinberg DA. Targeted actinium-225 in vivo generators for therapy of ovarian cancer. Cancer Res. 2003;63(16):5084-5090.

15. Miederer M, McDevitt MR, Sgouros G, Kramer K, Cheung NK, Scheinberg DA. Pharmacokinetics, dosimetry and toxicity of the targetable atomic generator, ${ }^{225} \mathrm{Ac}-\mathrm{HuM} 195$, in nonhuman primates. J Nucl Med. 2004;45(1):129-137.

16. Ballangrud ÅM, Yang WH, Palm S, et al. Alpha-particle emitting atomic generator (actinium-225)-labeled trastuzumab (Herceptin) targeting of breast cancer spheroids: efficacy versus HER2/neu expression. Clin Cancer Res. 2004;10(13):4489-4497.

17. Miederer M, McDevitt MR, Borchardt P, et al. Treatment of neuroblastoma meningeal carcinomatosis with intrathecal application of $\alpha$-emitting atomic nanogenerators targeting disialo-ganglioside GD2. Clin Cancer Res. 2004;10(20):6985-6992.

18. Yuan RR, Wong P, McDevitt MR, et al. Targeted deletion of T-cell clones using alpha-emitting suicide MHC tetramers. Blood. 2004;10(8):2397-2402.

19. Jurcic JG, McDevitt MR, Divgi CR, et al. Alpha-particle immunotherapy for acute myeloid leukemia (AML) with bismuth-213 and actinium-225. Cancer Biother Radiopharm. 2006;221(4):396.

20. Rosenblat TL, McDevitt MR, Pandit-Taskar N, et al. Phase I trial of the targeted alpha-particle nano-generator actinium-225 $\left({ }^{225} \mathrm{Ac}\right)$ HuM195 (Anti-CD33) in acute myeloid leukemia (AML). Blood. 2007; 110(11):277A. 
21. Miederer M, Scheinberg DA, McDevitt MR. Realizing the potential of the actinium-225 radionuclide generator in targeted alphaparticle therapy applications. Adv Drug Deliv Rev. 2008;60(12): 1371-1382.

22. McDevitt MR, Sgouros G, Finn RD, et al. Radioimmunotherapy with alpha-emitting radionuclides. Eur J Nucl Med. 1998;25(9): 1341-1351.

23. Nikula TN, McDevitt MR, Finn RD, et al. Alpha-emitting bismuth cyclohexylbenzyl DTPA constructs of recombinant humanized antiCD33 antibodies: pharmacokinetics, bioactivity, toxicity and chemistry. J Nucl Med. 1999;40(1):166-176.

24. Calabrese C, Poppleton H, Kocak M, et al. A perivascular niche for brain tumor stem cells. Cancer Cell. 2007;11(1):69-82.

25. Hambardzumyan D, Squatrito M, Carbajal E, Holland EC. Glioma formation, cancer stem cells, and akt signaling. Stem Cell Rev. 2008; 4(3):203-210.

26. Hambardzumyan D, Becher OJ, Rosenblum MK, Pandolfi PP, ManovaTodorova K, Holland EC. PI3 K pathway regulates survival of cancer stem cells residing in the perivascular niche following radiation in medulloblastoma in vivo. Genes Dev. 2008;22(4):436-448.

27. Jaggi JS, Henke E, Seshan SV, et al. Selective alpha-particle mediated depletion of tumor vasculature with vascular normalization. PLoS One. 2007;2(3):e267.

28. Nolan DJ, Ciarrocchi A, Mellick AS, et al. Bone marrow-derived endothelial progenitor cells are a major determinant of nascent tumor neovascularization. Genes Dev. 2007;21(12):1546-1558.

29. Verel I, Visser GW, Boellaard R, Stigter-van Walsum M, Snow GB, van Dongen GA. ${ }^{89} \mathrm{Zr}$ immuno-PET: comprehensive procedures for the production of ${ }^{89} \mathrm{Zr}$-labeled monoclonal antibodies. J Nucl Med. 2003; 44(8):1271-1281.

30. Holland JP, Sheh Y, Lewis JS. Standardized methods for the production of high specific-activity zirconium-89. Nucl Med Biol. 2009; 36(7):729-739.

31. Holland JP, Williamson MJ, Lewis JS. Unconventional nuclides for radiopharmaceuticals. Mol Imaging. 2010;9(1):1-20.

32. Holland JP, Caldas-Lopes E, Divilov V, et al. Measuring the pharmacodynamic effects of a novel Hsp90 inhibitor on HER2/neu expression in mice using Zr-DFO-trastuzumab. PLoS One. 2010;5(1): e8859.

33. Ruggiero A, Holland JP, Lewis JS, Grimm J. Cerenkov luminescence imaging of medical isotopes. J Nucl Med. 2010;51(7): 1123-1130.

34. Holland JP, Divilov V, Bander NH, Smith-Jones PM, Larson SM, Lewis JS. ${ }^{89} \mathrm{Zr}$-DFO-J591 for immunoPET of prostate-specific membrane antigen expression in vivo. J Nucl Med. 2010;51(8):1293-1300.

35. von Schulthess GK, Steinert HC, Hany TF. Integrated PET/CT: current applications and future directions. Radiology. 2006;238(2):405-422.

36. Georgakilas V, Tagmatarchis N, Pantarotto D, Bianco A, Briand JP, Prato M. Amino acid functionalization of water soluble carbon nanotubes. Chem Commun (Camb). 2002;(24):3050-3051.

37. Tasis D, Tagmatarchis N, Bianco A, Prato M. Chemistry of carbon nanotubes. Chem Rev. 2006;106(3):1105-1136.

38. Singh P, Campidelli S, Giordani S, Bonifazi D, Bianco A, Prato M. Organic functionalisation and characterisation of single-walled carbon nanotubes. Chem Soc Rev. 2009;38(8):2214-2230.

39. Singh R, Pantarotto D, Lacerda L, et al. Tissue biodistribution and blood clearance rates of intravenously administered carbon nanotube radiotracers. Proc Natl Acad Sci U S A . 2006;103(9):3357-3362.

40. Allen BL, Kichambare PD, Gou P, et al. Biodegradation of single-walled carbon nanotubes through enzymatic catalysis. Nano Lett. 2008;8(11): 3899-3903.

41. Allen BL, Kotchey GP, Chen Y, et al. Mechanistic investigations of horseradish peroxidase-catalyzed degradation of single-walled carbon nanotubes. J Am Chem Soc. 2009;131(47): 17194-17205.
42. Konduru NV, Tyurina YY, Feng W, et al. Phosphatidylserine targets single-walled carbon nanotubes to professional phagocytes in vitro and in vivo. PLoS One. 2009;4(2):e4398.

43. Kagan VE, Konduru NV, Feng W, et al. Carbon nanotubes degraded by neutrophil myeloperoxidase induce less pulmonary inflammation. Nat Nanotechnol. 2010;5(5):354-359.

44. Dumortier H, Lacotte S, Pastorin G, et al. Functionalized carbon nanotubes are non-cytotoxic and preserve the functionality of primary immune cells. Nano Lett. 2006;6(7):1522-1528.

45. Sayes CM, Liang F, Hudson JL, et al. Functionalization density dependence of single-walled carbon nanotubes cytotoxicity in vitro. Toxicol Lett. 2006;161(2):135-142.

46. Schipper ML, Nakayama-Ratchford N, Davis CR, et al. A pilot toxicology study of single-walled carbon nanotubes in a small sample of mice. Nat Nanotechnol. 2008;3(4):216-221.

47. Kostarelos K. The long and short of carbon nanotube toxicity. Nat Biotechnol. 2008;26(7):774-776.

48. McDevitt MR, Ma D, Simon J, Frank RK, Scheinberg DA. Design and synthesis of actinium-225 radioimmunopharmaceuticals. Appl Radiat Isot. 2002;57(6):841-847.

49. Hilmas DE, Gillette EL. Morphometric analyses of the microvasculature of tumors during growth and after x-irradiation. Cancer. 1974; 33(1):103-110.

50. Haas TL, Duling BR. Morphology favors an endothelial cell pathway for longitudinal conduction within arterioles. Microvasc Res. 1997;53(2): 113-120.

51. Folkman J. Tumor angiogenesis and tissue factor. Nat Med. 1996; 2(2):167-168

52. Folkman J. Anti-angiogenesis: new concept for therapy of solid tumors. Ann Surg. 1972;175(3):409-416.

53. Denekamp J. Endothelial cell proliferation as a novel approach to targeting tumor therapy. Br J Cancer. 1982;45(1):136-139.

54. Denekamp J. Review article: angiogenesis, neovascular proliferation and vascular pathophysiology as targets for cancer therapy. Br J Radiol. 1993;66(783):181-196.

55. Burrrows FJ, Thorpe PE. Vascular targeting - a new approach to the therapy of solid tumors. Pharmacol Ther. 1994;64(1):155-174.

56. Folkman J. Addressing tumor blood vessels. Nat Biotechnol. 1997; 15(6):510.

57. Kerbel RS. Antiangiogenic therapy: a universal chemosensitization strategy for cancer? Science. 2006;312(5777):1171-1175.

58. Cai W, Chen X. Multimodality molecular imaging of tumor angiogenesis. J Nucl Med. 2008;49 Suppl 2:113S-128S.

59. Dobrucki LW, de Muinck ED, Lindner JR, Sinusas AJ. Approaches to multimodality imaging of angiogenesis. J Nucl Med. 2010;51 Suppl 1: $66 \mathrm{~S}-79 \mathrm{~S}$.

60. Leunig M, Yuan F, Menger MD, et al. Angiogenesis, microvascular architecture, microhemodynamics, and interstitial fluid pressure during early growth of human adenocarcinoma LS174T in SCID mice. Cancer Res. 1992;52(23):6553-6560.

61. Kennel SJ, Mirzadeh S. Vascular targeted radioimmunotherapy with 213Bi-an alpha-particle emitter. Nucl Med Biol. 1998;25(3): $241-246$.

62. Kennel SJ, Lankford TK, Foote LJ, Davis IA, Boll RA, Mirzadeh S. Combination vascular targeted and tumor targeted radioimmunotherapy. Cancer Biother Radiopharm. 1999;14(5):371-379.

63. Kennel SJ, Chappell LL, Dadachova K, et al. Evaluation of ${ }^{225}$ Ac for vascular targeted radioimmunotherapy of lung tumors. Cancer Biother Radiopharm. 2000;15(3):235-244.

64. Kennel SJ, Mirzadeh S, Eckelman WC, et al. Vascular-targeted radioimmunotherapy with the alpha-particle emitter ${ }^{211}$ At. Radiat Res. 2002;157(6):633-641.

65. Nagengast WB, de Vries EG, Hospers GA, et al. In vivo VEGF imaging with radiolabeled bevacizumab in a human ovarian tumor xenograft. J Nucl Med. 2007;48(8):1313-1319. 
66. Stollman TH, Scheer MG, Leenders WP, et al. Specific imaging of VEGF-A expression with radiolabeled anti-VEGF monoclonal antibody. Int J Cancer. 2008;122(10):2310-2314.

67. Nayak TK, Garmestani K, Baidoo KE, Milenic DE, Brechbiel MW. PET imaging of tumor angiogenesis in mice with VEGF-A targeted (86)Y-CHX-A"-DTPA-bevacizumab. Int J Cancer. In press 2010.

68. Nikula TK, Bocchia M, Curcio MJ, et al. Impact of the high tyrosine fraction in complementarity determining regions: measured and predicted effects of radioiodination on IgG immunoreactivity. Mol Immunol. 1995;32(12):865-872.
69. Nilsson F, Kosmehl H, Zardi L, Neri D. Targeted delivery of tissue factor to the ED-B domain of fibronectin, a marker of angiogenesis, mediates the infarction of solid tumors in mice. Cancer Res. 2001;61(2): 711-716.

70. Baumgartner W, Drenckhahn D. Plasmalemmal concentration and affinity of mouse vascular endothelial cadherin. Eur Biophys J. 2002;31(7): $532-538$.

\section{Publish your work in this journal}

The International Journal of Nanomedicine is an international, peerreviewed journal focusing on the application of nanotechnology in diagnostics, therapeutics, and drug delivery systems throughout the biomedical field. This journal is indexed on PubMed Central, MedLine, CAS, SciSearch $\AA$, Current Contents ${ }^{\circledR} /$ Clinical Medicine,
Journal Citation Reports/Science Edition, EMBase, Scopus and the Elsevier Bibliographic databases. The manuscript management system is completely online and includes a very quick and fair peer-review system, which is all easy to use. Visit http://www.dovepress.com/ testimonials.php to read real quotes from published authors. 